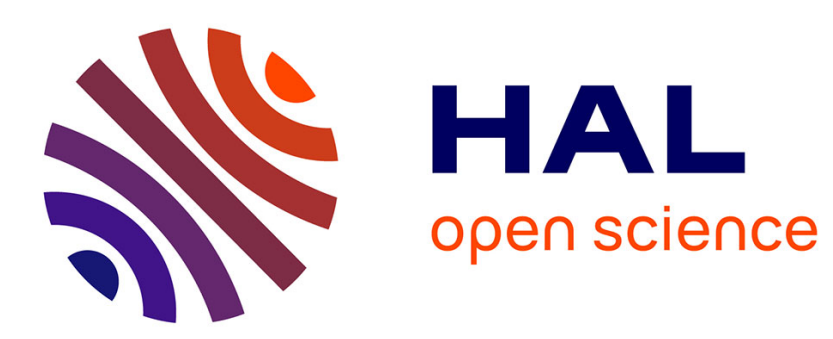

\title{
An experimental and numerical study of the aeolian erosion of isolated and successive piles
}

M.C.S. Ferreira, B. Furieri, J.M. Santos, A.O. El Moctar, J.-L. Harion, Alexandre Valance, P. Dupont, N.C. Reis

\section{To cite this version:}

M.C.S. Ferreira, B. Furieri, J.M. Santos, A.O. El Moctar, J.-L. Harion, et al.. An experimental and numerical study of the aeolian erosion of isolated and successive piles. Environmental Fluid Mechanics, 2020, 20 (1), pp.123-144. 10.1007/s10652-019-09702-z . hal-02281685

HAL Id: hal-02281685

https://hal-univ-rennes1.archives-ouvertes.fr/hal-02281685

Submitted on 24 Mar 2021

HAL is a multi-disciplinary open access archive for the deposit and dissemination of scientific research documents, whether they are published or not. The documents may come from teaching and research institutions in France or abroad, or from public or private research centers.
L'archive ouverte pluridisciplinaire HAL, est destinée au dépôt et à la diffusion de documents scientifiques de niveau recherche, publiés ou non, émanant des établissements d'enseignement et de recherche français ou étrangers, des laboratoires publics ou privés. 


\title{
An experimental and numerical study of the aeolian erosion of isolated and successive piles
}

\author{
M.C.S. Ferreira - B. Furieri · J.M. \\ Santos • A. Ould El Moctar • J.-L. \\ Harion • A. Valance • P. Dupont • N.C \\ Reis Jr \\ Received: date / Accepted: date
}

\begin{abstract}
Open storage yards at industrial sites usually comprise several piles of granular materials, representing a particulate matter source that may significantly deteriorate air quality. The aeolian erosion of stockpiles is affected by changes in airflow patterns due to the pile shape and the presence of nearby piles or buildings. The aim of this study was to analyse the impact of wind erosion of successive parallel stockpiles on flow behaviour and particle emissions. A wind tunnel experiment was conducted in six configurations: one isolated pile and two successive piles separated by gaps of $0.9 h$ and $1.8 h$ ( $h$ is the pile height) oriented to $60^{\circ}$ and $90^{\circ}$ with respect to the main wind flow direction. The particles in the piles had a bimodal particle size distribution consisting of sand that was erodible (white) and non-erodible (black) in the investigated velocity range. The contrasting colours enabled the visualisation of the non-erodible sand accumulation. The mean field of the wall shear stress distribution and flow pathlines predicted by numerical simulation were associated with the experimental erosion patterns. The emitted mass was experimentally quantified as the difference between the initial and final
\end{abstract}

M.C.S. Ferreira

Instituto Federal do Espírito Santo, 29056-255 Vitória, ES, Brazil

B. Furieri

Universidade Federal do Espírito Santo, DEA, 29060-970 Vitória, ES, Brazil E-mail: bruno.furieri@ufes.br

J.M. Santos

Universidade Federal do Espírito Santo, DEA, 29060-970 Vitória, ES, Brazil

A. Ould El Moctar

Polytech. Nantes, Laboratoire de Thermocinétique, F-44306 Nantes, France

J.-L. Harion

IMT Lille Douai, EI, F-59500 Douai, France

A. Valance

Universit de Rennes 1, Institut de Physique, F-35042 Rennes, France

P. Dupont

INSA de Rennes, LGCGM, F-35043 Rennes, France

N.C Reis Jr

Universidade Federal do Espírito Santo, DEA, 29060-970 Vitória, ES, Brazil 
stockpile weights. Downstream pile had a large impact on the aeolian erosion as it was highly eroded as a result of the impact of the particles emitted from the upstream pile. The emissions of the two consecutive stockpiles were greater than twice the emissions from an isolated stockpile for both orientations. Additionally, emissions were lower for configurations in which the piles were perpendicular.

Keywords Wind Erosion · Pavement · Fugitive Emissions · Turbulent flow · Wind Tunnel $\cdot$ Emission Measurements

\section{Introduction}

Diffuse emission from the aeolian erosion of granular materials from stockpiles or exposed granular beds may be difficult to quantify due to the large extension and shapes of the sources and the factors that affect the process such as atmospheric conditions (e.g., wind velocity and direction, precipitation, humidity and temperature), particle size distribution, modification of the wind flow due to the presence of obstacles and topography (e.g., flat or inclined surfaces). Granular materials typically have a wide particle size distribution, including larger grains that may not be lifted by wind. As erosion occurs, the concentration of the coarser particles on the pile surface increases. It has been verified that the accumulation of these grains plays a protective role in particle emissions, whether on a flat or an inclined surface [13, 21, 28, 29, 38]. Non-erodible particles create wake zones, reducing the drag on pile zones that would otherwise be erodible. A temporal decrease thereby occurs for the emitted mass flux, and the total amount of particles emitted due to wind erosion is strongly reduced, which is known as the pavement phenomenon.

The most widely used methodology to estimate fugitive dust emissions has been developed by the USEPA (United States Environmental Protection Agency) [35], based on data from wind tunnel experiments for two geometries of isolated stockpiles and three wind flow directions, and does not consider the pavement phenomenon. The rapid decrease in aeolian emissions linked to a wide size distribution is mentioned in USEPA [35], but it is not explicitly incorporated in the proposed method. The particle size distribution is also not explicitly incorporated into the method. So, if the model was applied to two granular materials with very different particle size distributions but the same maximum particle diameter, it would result in similar emission values. Experimental results show that wind erosion emissions can be widely different with the same maximum particle diameter but a greater proportion of larger particles which are non-erodible. Furthermore, the various configurations of different piles shapes that can be found at industrial sites are not covered by the elements provided by USEPA [35]. Industrial facilities usually contain more than one storage pile, which greatly affects erosion patterns since piles act as obstacles to the free path of atmospheric flow, modifying the flow field dynamics. Therefore, it is important to broaden the models application to more realistic situations. Several researchers have already performed this using both numerical (Computation Fluid Dynamics - CFD) and experimental (wind tunnel) approaches to investigate the physical phenomenon of wind erosion of granular materials beds and storage piles [8, 16, 17, 22, 24, 25, 32, 37, 39].

Badr and Harion [3] and Torano et al. [30] numerically predicted the wind flow over isolated piles in different scenarios with various geometries and wind 
orientations and used the USEPA formulation for the emission factor to quantify particle emissions using the friction velocity previously calculated by CFD. Turpin and Harion [33] investigated the flow structures over coal stockpiles in an actual power plant configuration. The authors performed numerical simulations in a configuration that included three coal stockpiles and different buildings in the surrounding area, and found that upstream buildings significantly increased emissions from the piles. Nevertheless, if the stockpile was located upstream of the buildings in the configurations tested by Turpin and Harion [33], then the erosion processes was slightly attenuated by a flow stagnation zone upstream of the buildings. The authors concluded that all wind perturbations including surrounding buildings and stockpiles have an impact, and must be accounted for in dust emissions estimation. Diego et al. [6] and Cong et al. [5] employed similar techniques to estimate dust emissions by integrating CFD data into the USEPA methodology. The former work studied the wind flow around an arrangement of two parallel flat-crested stockpiles separated by a gap of $0.44 h$ (where $h$ is the height of the piles) and highlighted the different contribution from each pile to the total eroded dust. The latter work evaluated dust emissions in an open yard with a complex geometry (16 stockpiles arranged in 4 columns) varying the pile shape (flat-topped oval and conical), the gap between the piles (0.6h and $1.2 h)$ and the orientation of the wind direction (from 0 to $90^{\circ}$ ). In both studies, a sheltering effect created by the neighbouring piles was noticed, which resulted in lower dust emissions. It is found that the front pile created a downstream shelter, then the wind velocity over the back pile was reduced. However, Cong et al. [5] verified that the total dust emissions are greater when the gaps between piles are larger. The authors implied that a gap larger than the shelter area completely exposes the downstream piles to wind erosion, similar to an isolated pile. In addition, it has been suggested that more studies with arbitrary space variation between the piles are necessary to better understand the role of the stockpile layout in limiting wind erosion in an actual yard. Furieri et al. [11] compared emissions (using CFD and emission factors) from an isolated and two successive oblong stockpiles separated by $0.9 h$ and $1.8 h$ gaps oriented by $60^{\circ}$ to the main wind flow direction. Numerical results showed that an isolated stockpile emitted less dust than each pile in the successive pile configuration. Therefore, a protective role of the upstream pile was not observed. Ferreira and Fino [7] performed wind tunnel experiments to study the erosion of an isolated sinusoidal pile and the interference effect resulting from two closely spaced piles (gaps of 0 and $h$ ). The authors found that the aeolian erosion of the downstream pile was considerably larger due to flow disturbances induced by the first pile. Therefore, the literature is contradictory, and the wind erosion of two parallel piles still requires additional investigation.

This study aimed to investigate, through numerical and experimental approaches, the impact of several configurations of parallel piles on wind erosion and the effect on emissions of the proportion of non-erodible particles. The parameters analysed were (i) wind velocity, (ii) the orientation of the piles to the main flow direction and (iii) the gap distance between the piles. A wind tunnel experiment was performed to estimate and compare emissions from an isolated sand pile and from two successive piles. The particles that constituted the piles had a bimodal particle size distribution encompassing erodible and non-erodible particles in two different proportions. The accumulation of non-erodible particles enabled an analysis of the erosion patterns of the piles. Numerical simulations with 
identical configurations were carried out to obtain the wall shear stress distribution on the pile surface and the flow pathlines, which support our understanding of the physical phenomena.

\section{Experimental study}

The experiment was conducted in the wind tunnel facilities at the Industrial Energy Department (IMT Lille Douai, France). Figure 1 shows the experimental set-up and the principal dimensions of the wind tunnel. Multiple roughness obstacles were placed in rows close to the tunnel entrance to enable the formation of a turbulent boundary layer. The validation of the experimental profiles upstream the test section is based on the comparison between measured profiles of velocity and turbulent kinetic energy (carried out in the same wind tunnel by Turpin [31] and Furieri et al. [12]) and the profiles of fully developed turbulent boundary layer from the literature [26]. In the vicinity of the wall, the velocity profile follows the linear law and then, moving away from the wall, follows the logarithmic law. The wind-tunnel generates a fully developed turbulent boundary layer at the level of the measurement zone with a thickness greater than the stockpile height $(\delta=16$ $\mathrm{cm}>h=7.7 \mathrm{~cm})$. More details of the wind-tunnel characteristics are given by Furieri et al. [12] and Turpin [31]. The Reynolds number of the fluid flow inside the wind-tunnel is approximately between 36000 and 48000 based on the free stream velocity (from 6 to $8 \mathrm{~m} / \mathrm{s}$ ) and stockpile height.

A bimodal granulometry of sand with density equal to $2650 \mathrm{~kg} / \mathrm{m}^{3}$ was used to represent erodible and non-erodible particles: fine white sand and coarse black sand with ranges of diameters from 56.0 to $194.2 \mu \mathrm{m}$ and from 700.0 to 1300.0 $\mu m$, respectively. The sand colours allowed the visualisation of high shear stress zones, which were marked by the accumulation of non-erodible particles.

The threshold friction velocities $u_{t \text { min }}^{*}$ and $u_{t \text { max }}^{*}$ at which the largest erodible particles $(194.2 \mu \mathrm{m})$ and the smallest non-erodible particles $(700.0 \mu \mathrm{m})$, respectively, are lifted from a horizontal surface were calculated using the take-off criterion obtained by Shao and $\mathrm{Lu}[27]$ :

$$
u_{t_{s}}^{*}=0.11 \sqrt{\frac{\rho_{P}-\rho}{\rho} g D+\frac{\gamma}{\rho D}},
$$

where $u_{t_{s}}^{*}$ is the threshold friction velocity, $\rho$ is the fluid density, $\rho_{P}$ is the particle density, $g$ is the gravity, $D$ is the particle diameter and $\gamma$ is a surface energy that characterises the cohesion. Shao and $\mathrm{Lu}$ [27] recommended values of $\gamma$ ranging between $1.65 \times 10^{-4}$ and $5.00 \times 10^{-4} \mathrm{~kg} / \mathrm{s}^{2}$. In the present work, $\gamma=2.86 \times$ $10^{-4} \mathrm{~kg} / \mathrm{s}^{2}$ was adopted. This value was calculated by fitting Equation 1 to the experimental threshold required to lift loose particles as proposed by Kok and Renno [19].

Figure 2 shows the take off-criterion, the fine and coarse sand size ranges used for the experiments and the friction velocities $u_{t \text { min }}^{*}=0.23 \mathrm{~m} / \mathrm{s}$ and $u_{t \max }^{*}=0.42$ $\mathrm{m} / \mathrm{s}$. The corresponding freestream flow velocities $U_{\min }$ and $U_{\max }$, determined based on $u_{\min }^{*}$ and $u_{\max }^{*}$, were calculated using the expression proposed by Kurose and Komori [20]: 


$$
u^{*}=u_{\text {smooth }}^{*}\left(1+0.00431 h^{+}\right) \text {, }
$$

where $h^{+}$is the dimensionless mean diameter of the non-erodible particles $\left(h^{+}=\right.$ $h_{N E P} u_{s}^{*} / \nu$, where $h_{N E P}$ is the mean diameter of the non-erodible particles, and $\nu$ is the kinematic viscosity), and $u_{\text {smooth }}^{*}$ is the friction velocity in a smooth wall. It is calculated by the relation proposed by Mollinger and Nieuwstadt [23]:

$$
u_{\text {smooth }}^{*}=0.036 U_{\infty}+0.033 .
$$

Equation 2 represents the effects of roughness elements on the vertical velocity profiles. Specifically, in the present experiments the roughness length is assumed to be the diameter of the coarse (non-erodible) particles. Therefore, Equations 2 and 3 yielded $U_{\min }=5.5 \mathrm{~m} / \mathrm{s}$ and $U_{\max }=9.5 \mathrm{~m} / \mathrm{s}$. Three different velocities were experimentally tested: 6,7 and $8 \mathrm{~m} / \mathrm{s}$. These velocities were between $U_{m i n}$ and $U_{\max }$, the minimum and maximum velocities at which the finer and the coarse particles remained erodible and non-erodible, respectively, for a horizontal surface. However, the threshold friction velocity $u_{t_{s}}^{*}(\theta)$ on a surface with a slope $\tan \theta$ is different from that found in a flat bed due to the distinct relative contributions of the forces acting on the particle. If the slope is positive (flow upwards), gravity is a resistive force, and thus, the friction velocity must be stronger to lift the grains. In contrast, if the slope is negative (flow downwards), the friction velocity required to lift the particles is lower than the threshold friction velocity for the beds.

The sand stockpile models were formed inside the wind-tunnel using a device similar to an industrial hopper, shown in Figure 3(a). Furieri et al. [13] have performed several tests to ensure that the pile shape and dimensions given by this device were reproducible. The dimensions of the sand stockpile had a scale ratio of approximately 1:200 to an actual stockpile, and they are shown in Figures 3(b) and $3(\mathrm{c}): 7.7 \mathrm{~cm}$ (height), $23.6 \mathrm{~cm}$ (length), $57.9 \mathrm{~cm}$ (width), and $34.5^{\circ}$ of angle of repose. It must be mentioned that the experiments did not accurately simulate full-scale conditions because the pile dimensions were smaller than the saturation length, the length that transport requires for saturation (i.e., to reach the saturated flux), which is approximately 1 to $2 m$ [1]. Therefore, the experimental sand piles did not behave in a similar way to piles of scale several metres from the erosion point of view: the first would be primarily eroded by aerodynamic entrainment, while the second would be subject to impact entrainment.

Configurations of one isolated stockpile and two successive stockpiles were used in the wind tunnel experiments. For the two pile configuration, the edge-to-edge separations tested were $0.9 h$ and $1.8 h$, where $h$ is the height of the pile. The effect of the stockpile orientation to the main wind flow direction was analysed for $60^{\circ}$ and $90^{\circ}$. The piles were built with a mixture of the erodible and non-erodible sand with two different mass fractions of non-erodible particles $\left(\alpha_{N E}\right): 10$ and $20 \%$. The six pile configurations used in the 36 tests are shown in Table 1.

After determining the initial stockpile mass and setting it on the wind tunnel floor, the free stream velocity was set by a frequency controller, and the fan was turned on. The duration of the flow was 15 minutes in all cases. No additional emissions occurred after this period, and a progressive pavement process that 
finally suppressed erosion at the eroded areas was observed. A camera installed over the wind-tunnel ceiling (transparent glass wall) registered the erosion evolution by analysing the contrasting colours (black and white sand). The photographs were taken at the beginning of the experiment and every 30 seconds for 5 minutes. The last picture was taken after 15 minutes. These pictures allowed for a qualitative assessment of the temporal evolution of different wind erosion exposure zones on the pile.

For the two parallel pile configuration, each pile was weighed separately after the experiment. The mass of particles emitted was calculated as the difference between the initial and final stockpile weights.

The repeatability of the experimental measurements was tested using the configuration with $\alpha_{N E}=20 \%$, orientation $90^{\circ}, 1.8 \mathrm{~h}$ gap and $U_{\infty}=7 \mathrm{~m} / \mathrm{s}$. The emitted mass for the three different tests of repetitions had a reasonable coefficient of variation equal to $4.5 \%$ (the coefficient of variation is defined as the ratio of the standard deviation to the mean and is given by 23.3 and 524.3 grams, respectively).

\section{Numerical simulations set up}

Numerical simulations were performed to solve the flow structure over several pile configurations representing the wind tunnel experiment (see Table 1). The threedimensional Reynolds Averaged Navier-Stokes equations of mass and momentum were solved using the commercial software Fluent 15.0 [10], providing the mean fields of the flow properties. The $k-\omega$ Shear Stress Transport (SST) model was used to incorporate turbulence effects. The governing equations of transport are described below.

- Continuity equation:

$$
\frac{\partial\left(\rho u_{i}\right)}{\partial x_{i}}=0
$$

Where, $t$ represents the time $[s] ; \rho$ is the specific mass of the fluid $\left[\mathrm{kg} / \mathrm{m}^{3}\right] ; u_{i}$ is the instant component of the velocity in the $i$ direction $\left[\mathrm{m} / \mathrm{s}^{1}\right] ; x_{i}$ identifies the coordinate in the direction $i[m]$.

- Momentum conservation:

$$
\begin{gathered}
\frac{\partial\left(\rho u_{i} u_{j}\right)}{\partial x_{j}}=\frac{\partial \tau_{i j}}{\partial x_{j}}-\rho \delta_{3 i} g \\
\tau_{i j}=2 \mu S_{i j}-\left(p+\frac{2}{3} \mu \frac{\partial u_{k}}{\partial x_{k}} \delta_{i j}\right) \\
S_{i j}=\frac{1}{2}\left(\frac{\partial u_{i}}{\partial x_{j}}+\frac{\partial u_{j}}{\partial x_{i}}\right)
\end{gathered}
$$

Where, $\delta_{i j}$ represents the Kronecker Delta, $g$ is the acceleration of gravity $\left[\mathrm{m} / \mathrm{s}^{2}\right], p$ is the mechanical pressure $\left[N / \mathrm{m}^{2}\right], \tau_{i j}$ is the stress tensor $\left[N / \mathrm{m}^{2}\right], \mu$ is the molecular viscosity $[\mathrm{kg} / \mathrm{m} . \mathrm{s}]$ and $S_{i j}$ is strain rate tensor $[1 / \mathrm{s}]$.

A variant of the $\mathrm{k}-\omega$ model is the $\mathrm{k}-\omega S S T$ (Shear Stress Transport) model. Boussinesq hypothesis is used in the turbulence closure model. The k- $\omega S S T$ is 
indicated for flow with adverse pressure gradients. This model includes two modifications: (i) The turbulent kinematic viscosity is modified according to equation 10 which best represents the shear stress transport effects for this type of flow and (ii) the addition of a term in the equation 9 of the diffusion of $\omega$ is a specific function that allows the validity of the equations in the zones near the wall or distant.

The model uses the following two transport equations for $k$ and $\omega$ :

$$
\begin{gathered}
\frac{\partial k}{\partial t}+\frac{\partial k}{\partial x_{j}}\left(\bar{u}_{j}\right)=P_{k}-\beta^{*} k \omega Y_{k}+\frac{\partial}{\partial x_{j}}\left[\left(\nu+\sigma_{k} \nu_{t}\right) \frac{\partial k}{\partial x_{j}}\right] \\
\frac{\partial \omega}{\partial t}+\frac{\partial \omega}{\partial x_{j}}\left(\bar{u}_{j}\right)=\alpha S^{2}-\beta \omega^{2}+\left[\left(\nu+\sigma_{\omega} \nu_{t}\right) \frac{\partial \omega}{\partial x_{j}}\right]+2\left(1-F_{1}\right) \sigma_{\omega 2} \frac{1}{\omega} \frac{\partial k}{\partial x_{i}} \frac{\partial \omega}{\partial x_{i}}
\end{gathered}
$$

Where the coefficients and auxiliary relations are given by:

$$
\begin{gathered}
\nu_{t}=\frac{a_{1} k}{\max \left(a_{1} \omega, S F_{2}\right)} \\
F_{1}=\tanh \left[\left[\min \left[\max \left(\frac{2 \sqrt{k}}{\beta^{*} \omega y}, \frac{500 \nu}{y^{2} \omega}\right), \frac{4 \sigma_{\omega 2} k}{C D_{k \omega} y^{2}}\right]^{4}\right]\right] \\
C D_{k \omega}=\max \left(2 \rho \sigma_{\omega 2} \frac{\partial k}{\partial x_{i}} \frac{\partial \omega}{\partial x_{i}}, 10^{-10}\right) \\
F_{2}=\tanh \left[\left[\max \left(\frac{2 \sqrt{k}}{\beta^{*} \omega y}, \frac{500 \nu}{y^{2} \omega}\right)\right]^{2}\right] \\
P_{k}=\min \left[\min \left(\tau_{i j} \frac{\partial u_{i}}{\partial x_{j}}, 10 \beta^{*} k y\right), C_{l i m} \rho \epsilon\right]
\end{gathered}
$$

The tensor of the turbulent stresses is treated as:

$$
\left.\tau_{i, j}=\mu_{t}\left(\frac{\partial u_{i}}{\partial x_{j}}+\frac{\partial u_{j}}{\partial x_{i}}-\frac{2}{3} \frac{\partial u_{k}}{\partial x_{k}} \delta_{i, j}\right)-\frac{2}{3} \rho k \delta_{i, j}\right]
$$

The constants of k- $\omega S S T$ model are summarized as follows: $\sigma_{k}=0.85 ; \sigma_{k, 1}=$ $1.0 ; \sigma_{\omega, 1}=0.5 ; \sigma_{\omega, 2}=0.856 ; \beta_{1}=0.075 ; \beta_{2}=0.0828 ; \beta^{*}=0.09 ; \alpha_{\infty, 1}=\frac{5}{9} ; \alpha_{\infty, 2}=$ $0.44 ; a_{1}=0.31 ; C_{\text {lim }}=10$.

This turbulence model was chosen based on a study performed by Badr and Harion [2], who simulated analogous configurations under similar flow conditions and compared the results using different closure models. Figure 4 presents the computational domain dimensions and boundary conditions. The numerical model of the stockpile presents a not evolving surface during erosion. The pile retained its shape during erosion in the proposed model. A no-slip condition was set at this boundary. The inlet boundary conditions for the velocity, the turbulent kinetic energy and the specific dissipation rate were retrieved from a converged field obtained by previous numerical simulations of a flat plane surface with the same dimensions, for which a periodic streamwise flow was set. In these precursors numerical simulations, we imposed a mass flow rate correspondent to the desired free stream velocity. The converged vertical velocity profile is logarithmic. The 
inlet profiles of wind velocity and turbulence of the numerical simulations were validated using the experimental data carried out by Turpin [31] in the same wind tunnel described in Section 2. A fully developed flow was assumed for the outflow conditions, that is, all flow variables except pressure were assumed to have a zero normal gradient. The SIMPLEC algorithm was used for pressure-velocity coupling [36]. Symmetry conditions were applied to the upper domain boundary (normal gradients of all variables were set to zero). Finally, no-slip conditions were imposed for the lateral boundaries, the ground and the pile surface.

The geometries and meshing were generated with Gambit software (Geometry and Mesh Building Intelligent Toolkit) [9]. The mesh was built by an extrusion of triangular face cells from the pile and ground walls towards the upper wall of the computational domain creating triangular-based prism cells (see Figure 5). The grid is irregular following the shape and orientation of the geometries. A mesh refinement near the walls $(y+<5)$ was required due to the expected intense gradients close to these areas and due to turbulence modelling requirements. Mesh sensitivity tests were previously carried out for similar configurations [2]. Turbulence model choice was based on previously validated numerical calculations performed by Badr and Harion [2] and Turpin et al. [34]. For the different configurations, the computational grids ranged from 3800000 to 5300000 cells. The simulations with two successive piles arrangement required the larger number of cells in order to allow sufficient refinement between the piles.

\section{Results}

The results are presented in three sections. In the first section, the erosion patterns are interpreted in the light of the numerical data of the basal shear stress map. Then, a general overview of the pavement process for a tested case is presented. Finally, the mass loss measurements for the different configurations are discussed in the third section.

\subsection{Comparison between basal shear stress maps and erosion patterns}

As previously mentioned, the erosion patterns were identified by the agglomeration of non-erodible (black) particles in the final experimental images, after the pavement phenomenon. The surface distribution of the black particles enabled the identification of pile zones in which the shear stress was great enough to erode fine particles (i.e., white particles) and offers support to the investigation of the effect of a second stockpile on the erosion pattern. This section mainly focuses on the experiment in which the wind erosion was more evident $\left(U_{\infty}=8 \mathrm{~m} / \mathrm{s}\right.$ and $\alpha_{N E}=20 \%$ ) to highlight the erosion patterns in different areas of the piles surface.

The numerical results are presented in dimensionless form as local shear stress values were divided by a reference shear stress value $\left(\tau_{r e f}\right)$ obtained for an undisturbed zone where the flow was not affected by the stockpile. Although the shear stress increased with an increase of the wind flow velocity, the flow pattern characteristics given by $\tau / \tau_{r e f}$ remained quite similar for each velocity tested. Similarly, 
the mean fluid flow pathlines around the piles were coloured based on the ratio of the velocity to a reference free stream velocity $\left(U_{\infty}\right)$.

The isolated stockpile will subsequently be referred to as pile $p_{1}$, and the upstream and downstream piles in the successive arrangements will be referred to as piles $p_{2}$ and $p_{2}^{\prime}$, respectively. Distinctive wind erosion regions are highlighted according to the degree of wind exposure. To facilitate the analysis, 4 zones were highlighted on the isolated stockpile and are designated as $A_{1}, B_{1}, C_{1}$ and $D_{1}$, and 4 zones were highlighted on each pile for the successive configurations and are designated as $A_{2}, B_{2}, C_{2}$ and $D_{2}$ in pile $p_{2}$ and $A_{2}^{\prime}, B_{2}^{\prime}, C_{2}^{\prime}$ and $D_{2}^{\prime}$ in pile $p_{2}^{\prime}$.

\subsubsection{Stockpiles oriented perpendicularly to the main wind flow direction}

Figures 6 and 7 show the photographs taken after the pavement phenomenon, the mean wall shear stress distribution and pathlines, respectively, for an isolated stockpile and two stockpiles oriented $90^{\circ}$ to the main flow direction (separated by gaps of $0.9 h$ and $1.8 h)$.

Figure 6(a) shows that no erosion occurred in the stagnation zone $A_{1}$. Indeed, this zone was characterised by intense deceleration and wall shear stress levels near zero (see Figures 6(b) and 6(c)). The incident flow was progressively accelerated towards the crest and the lateral sides of the pile forming region $B_{1}$, where the highest levels of shear occurred due to a strong velocity gradient (Figures 6(b) and $6(\mathrm{c}))$. Therefore, these areas were the most vulnerable to wind erosion, which explains the accumulation of non-erodible black particles seen in Figure 6(a).

Figure 6(c) shows the flow separation from the pile surface on the crest and the lateral sides, as a result of a strong adverse pressure gradient. The separation led to a wake region downstream of the pile (zone $C_{1}$ ), with low wall shear stress levels and weak erosion (see Figures 6(a) and 6(b)). Figure 6(c) reveals two counterrotating vortices on the lateral sides that interact with the separation from the crest. The complex three-dimensional structures formed in this recirculating region created a small zone with higher shear (zone $D_{1}$ ), in which a slight accumulation of black sand was noticeable (see Figures 6(a) and 6(b)). Between the two main counter-rotating vortices there is a flow acceleration region that slightly affects the bottom of the leeward wall.

Similarly, Figures 7(b) and 7(c) show a deceleration upstream pile $p_{2}$ (region $A_{2}$, with low levels of shear) and a flow acceleration towards the slope and sides (region $B_{2}$, with high levels of shear). Nevertheless, especially for the gap of $0.9 h$, the dimensionless values of shear stress for the piles oriented $90^{\circ}$ (region $B_{2}$ ) were higher than for the pile with no interference (region $B_{1}$ ), with maximum values of 8.6 and 6.9 , respectively. These findings are consistent with the erosion patterns observed in Figure 7(a).

An asymmetrical pattern was detected in the experimental and numerical results, despite the symmetrical geometry. The literature reported similar behaviour of the flow around geometrical symmetric obstacles $[14,15,18,40]$ as a consequence of the bi-stable intermittent nature of the flow in which the wake switches randomly at irregular intervals from the sides of the pile between the two stable states. The numerical simulation of bi-stability is a difficult task, due to its very long timescale. The average timescale of the RANS numerical simulations may not be sufficiently large to comprise the switch of the wake timescale. 
Figure 7(a) revealed an accumulation of sand on the ground between the piles for the closely spaced configuration $(0.9 h$ gap). In addition, the interference of pile $p_{2}^{\prime}$ in the leeward wall of pile $p_{2}$ was more important in this case. When comparing the $0.9 \mathrm{~h}$ gap to the $1.8 \mathrm{~h}$ gap, the zone of ineffective erosion $C_{2}$ was smaller, and the black zone of high erosion $D_{2}$ was larger. For the $1.8 \mathrm{~h}$ gap, the wake region of pile $p_{2}$ resembled the wake region of pile $p_{1}$ and the extent of areas $C_{2}$ were comparable, except for the narrow region of high friction that was impacted by the vortex (zone $D_{2}$ ) that was transposed to the lateral side due to the bi-stability.

A more severe erosive impact was observed for the second stockpile on the windward wall of pile $p_{2}^{\prime}$. Figure 7 (a) shows that a very high concentration of black particles in this area, which indicates a zone vulnerable to erosion, particularly with the $0.9 h$ gap. In pile $p_{2}^{\prime}$, zone $B_{2}^{\prime}$ is the region with the highest shear stress values because of the impact of the vortex structure shown in Figure 7(c). On the other hand, zone $A_{2}^{\prime}$ has low shear level and the pathlines velocities were lower (see Figures 7(b) and 7(c)). Unexpectedly, the erosion patterns demonstrated that this zone was characterised by high erosion (see Figure 7(a)). Two possible mechanisms could explain this unexpected observation: the intermittent behaviour of the vortices due to bi-stability and the impact of the emitted particles from pile $p_{2}$.

In the wake zone behind pile $p_{2}^{\prime}$, the regions $C_{2}^{\prime}$ and $D_{2}^{\prime}$ were also highlighted. The similarity between these zones can be noticed for the $0.9 h$ and $1.8 h$ gaps; however, in both cases, $D_{2}^{\prime}$ is larger than the corresponding zone in pile $p_{1}$ (zone $D_{1}$ ), which emphasises the impact on the downstream pile.

\subsubsection{Stockpiles oriented $60^{\circ}$ to the main wind flow direction}

Figures 8 and 9 show the photographs after the pavement phenomenon, the mean fields of the wall shear stress distribution and the flow pathlines, respectively, an isolated stockpile and two stockpiles oriented $60^{\circ}$ to the main flow and separated by $0.9 h$ and $1.8 h$ gaps.

The wind exposure patterns were similar on piles $p_{1}$ and $p_{2}$ for the configurations oriented $60^{\circ}$ to the main flow direction. Progressive flow acceleration up the slope and towards the lateral sides was observed on the windward wall of these piles (see Figures $8(\mathrm{c})$ and $9(\mathrm{c})$ ). Zones $A_{1}$ and $A_{2}$ had low levels of shear and ineffective erosion whereas the opposite occurred in zones $B_{1}$ and $B_{2}$ (see Figures $8(\mathrm{a}), 8(\mathrm{~b}), 9(\mathrm{a})$ and $9(\mathrm{~b}))$. The highest friction levels in zones $B_{1}$ and $B_{2}$ were found on the lateral sides of the pile facing the wind. In addition, the shear peak values were higher for the $60^{\circ}$ orientation than for the $90^{\circ}$ orientation.

Figures $8(\mathrm{c})$ and $9(\mathrm{c})$ show that a single main helical vortex was formed downstream of the stockpiles $p_{1}$ and $p_{2}$. The flow separation near the crest of these piles led to a wake regions on the leeward wall (zone $C_{1}$ and $C_{2}$, respectively), with low wall shear stress levels and weak erosion (see Figures 8(a), 8(b), 9(a) and 9(b)). The impact of this vortex can be clearly observed in zones $D_{1}$ and $D_{2}$, a region with higher friction and significant agglomeration of black particles, although it had a weaker effect on pile $p_{1}$. Moreover, the vortex had a greater effect on the closely spaced piles. Indeed, it impinged on the windward $p_{2}^{\prime}$ pile wall increasing the friction on the upper part of region $B_{2}^{\prime}$.

The unexpected situation in zone $A_{2}^{\prime}$ with a low shear stress level and a high erosion rate was also seen for the $60^{\circ}$ orientation. This situation can be again 
attributed to the impact of the emitted particles from pile $p_{2}$. Further evidence supporting the effect of particles in saltation from pile $p_{2}$ on the erosion of pile $p_{2}^{\prime}$ can be seen in Figure 10, which shows the final photographs and the dimensional contours of the shear stress for the velocities 6 and $8 \mathrm{~m} / \mathrm{s}$ with the $1.8 \mathrm{~h}$ gap and $\alpha_{N E}=20 \%$. In this figure the results are presented in the dimensional form in order to compare the absolute values of the shear stress for both velocities. The highlighted area in zone $B_{2}$ (red line) was highly eroded for $U_{\infty}=8 \mathrm{~m} / \mathrm{s}$ due to the high levels of shear and the windward wall of pile $p_{2}^{\prime}$ was also highly eroded, as shown in Figure 10(a). Accordingly, as erosion is weaker for $U_{\infty}=6 \mathrm{~m} / \mathrm{s}$, the red region in zone $B_{2}$ and its corresponding directly frontal region in pile $p_{2}^{\prime}$ remained uneroded (see Figure 10(b)). Similarly, the upper part of region $A_{2}^{\prime}$ (highlighted with blue line) was highly eroded, suggesting emissions due to the impact of saltating particles from region $D_{2}$ of pile $p_{2}$.

A significant concentration of coarse black particles in the windward wall of pile $p_{2}^{\prime}$, as shown in Figure 9(a), reinforces the strong impact of a second parallel stockpile on erosion, especially for the smaller gap $(0.9 h)$.

The patterns on the leeward walls of pile $p_{2}^{\prime}$ behaved in a similar manner as the leeward walls of piles $p_{2}$ although with much less erosion intensity. In Figure 9 (a), zone $D_{2}$ is larger than zone $D_{2}^{\prime}$, especially for the $1.8 h$ gap.

\subsection{Visual analysis of the erosion patterns}

Figure 11 illustrates the experimental temporal evolution of wind erosion for both granulometries (with $\alpha_{N E}=10$ and 20\%) and for the lowest and highest wind velocities $\left(U_{\infty}=6\right.$ and $\left.8 \mathrm{~m} / \mathrm{s}\right)$. Considering that similar pavement phenomenon behaviour was observed for all arrangements, a configuration with an orientation $60^{\circ}$ and a $0.9 h$ gap was chosen to represent a typical case.

As mentioned in Section 2, the pavement phenomenon was observed after 15 minutes of wind exposure for all configurations, which means that the final erosion patterns are well represented in the fifth column of photographs shown in Figure 11. The extent of the final eroded areas varied little with the increase of $\alpha_{N E}$, although the final concentration of non-erodible particles in these areas was higher for $\alpha_{N E}=20 \%$ than for $\alpha_{N E}=10 \%$, especially for $U_{\infty}=8 \mathrm{~m} / \mathrm{s}$. On the other hand, a significant increase of the eroded areas occurred as flow velocity increased. For instance, modifications of the windward surface of the upstream pile are almost imperceptible for $U_{\infty}=6 \mathrm{~m} / \mathrm{s}$ whilst the same region was highly eroded for $U_{\infty}=8 \mathrm{~m} / \mathrm{s}$.

The temporal evolution of the pavement shown in the Figure 11 indicates that the phenomenon occurred faster in tests with a larger amount of non-erodible particles and higher velocities. Indeed, for $\alpha_{N E}=20 \%$ and $U_{\infty}=8 \mathrm{~m} / \mathrm{s}$, after 30 seconds a larger quantity of black particles accumulated than with $\alpha_{N E}=10 \%$ and $U_{\infty}=6 \mathrm{~m} / \mathrm{s}$, and after 1 minute and 30 seconds, the observed pattern was found to be very close to the final pattern. This behaviour was related to a temporal decrease in the emitted mass flux. The highest pavement rate for $\alpha_{N E}=20 \%$ supports previous findings in the literature [13]. 
4.3 Emission estimates

Table 2 shows the emitted mass measurements from an isolated stockpile $\left(p_{1}\right)$ and from each stockpile in the successive arrangement $\left(p_{2}\right.$ and $\left.p_{2}^{\prime}\right)$. The first result worth noting is the remarkable amount of sand emitted from the downstream pile $p_{2}^{\prime}$. In all test cases, the emissions were higher for the pile $p_{2}^{\prime}$, compared to either pile $p_{2}$ or $p_{1}$, which is consistent with the experimental erosion patterns discussed in Section 4.1. The reason for this result is the emissions from the upward wall of pile $p_{2}^{\prime}$ due to the impact of saltating particles from pile $p_{2}$ (see Figure 10).

Pile $p_{2}^{\prime}$ had higher emissions in the $60^{\circ}$ arrangement if the stockpiles were separated by a $0.9 h$ gap because of higher shear stress values, a greater effect of the main vortex shed from pile $p_{2}$ and interactions between the piles (more energetic saltation particles). These facts do not apply to pile $p_{2}$ (wall shear stress distribution on pile $p_{2}$ is quite similar for both gaps for the orientation of $60^{\circ}$ ), and the critical importance of the gap on the emitted mass for this pile was not observed. Nevertheless, the shear levels of pile $p_{2}$ were higher than those of pile $p_{1}$, and the amount of emitted mass was also higher.

On the other hand, with the piles oriented $90^{\circ}$ to the main flow, pile $p_{2}^{\prime}$ and pile $p_{2}$ had higher emissions for stockpiles separated by a gap distance of $1.8 h$. However, this result is ambiguous because, as mentioned in Section 4.1.1, an accumulation of sand in the floor between the piles was noticed for the $0.9 h$ gap. This mass was not counted in the balance as emitted because it was hard to distinguish from which pile it arose (it was even hard to separate the sand from the piles). For the same reason, a rigourous comparison of the emitted mass from piles $p_{2}$ (with $0.9 h$ gap) and $p_{1}$ is difficult; however, we noticed that the values were close. Nevertheless, emissions from pile $p_{2}$ were slightly lower for stockpiles separated by a gap distance of $1.8 h$ than from an isolated stockpile. Therefore, the emissions of each pile in the configuration with two piles depend on the orientation of the flow. It was only the upstream pile of a pair in the 90 orientation that experienced less erosion that an isolated pile.

Figure 12 shows the total emitted mass amount from successive stockpiles compared to twice the amount from an isolated stockpile (which could mimic a situation in an open industrial yard in which the piles are far enough away from each other to not interfere) for all tested configurations. The total amount from the two successive stockpiles was greater for both orientations, and in some cases, the emitted mass could be more than three times higher, compared to two times the value from an isolated pile.

Furthermore, Figure 12 highlights that erosion was greater in configurations with a main wind flow direction oriented $60^{\circ}$ than in those oriented $90^{\circ}$ to the piles, especially if the piles are separated by a gap distance of $0.9 \mathrm{~h}$. In addition, for the same value of the free stream velocity, emissions with $\alpha_{N E}=20 \%$ were approximately half that of emissions with $\alpha_{N E}=10 \%$. Therefore, the proportion of non-erodible particles has a considerable effect on particle emissions.

\section{Conclusion}

The purpose of this study was to investigate the aeolian erosion of stockpiles with a bimodal granulometry formed by erodible and non-erodible sand using wind tunnel 
experiments. Numerical simulations were performed to supply wind flow data (i.e., shear stress distribution and pathlines) in order to support an understanding of the phenomenon.

Temporal evolution of the pavement phenomenon was analysed using top view photographs of the piles, studying the progress of wind erosion exposure zones. It has been verified that the phenomenon occurred faster for larger amounts of non-erodible particles and higher velocities.

Wind flow modifications and their effects on wind erosion were numerically and experimentally assessed for two pile orientations to the main wind flow direction $\left(60^{\circ}\right.$ and $\left.90^{\circ}\right)$ and three different arrangements: an isolated stockpile and two successive stockpiles separated by $0.9 h$ and $1.8 h$ gaps. For the perpendicular arrangement it was observed highly eroded zones in which the incident flow accelerated on the crest and lateral sides and zones of weaker erosion downstream of the piles, after the flow separation. For the orientation of $60^{\circ}$, the erosion was stronger due to higher shear stress values and the effects of the main vortex on the leeward wall of the piles. A strong impact on the downstream pile was observed for both orientations. The downward wall of these piles had a highly eroded region, even though the shear stress values were low (zone $A_{2}^{\prime}$ ) due to the impact of the eroded particles from the upstream pile. Therefore, it is important to consider this behaviour in future numerical modelling studies. With the exception of zone $A_{2}^{\prime}$, good agreement was found between the numerical distribution of the wall shear stress and the agglomeration of non-erodible particles on the stockpile surface. The results indicate that, in addition to the wind velocity, the orientation of the pile to the prevailing wind direction also plays an important role to limit aeolian erosion in actual storage yards. Industries yards may redesign their piles arrangements according to the most frequent wind direction based on local meteorological data. Oblique piles shown to be more eroded when located near to each other. On the other hand, perpendicular piles presented a protective effect. It is a general recommendation that the stockpiles should be oriented perpendicular to the wind direction.

The experimental quantification of the mass emitted revealed that the emissions from two consecutive stockpiles are greater than twice the emissions from an isolated stockpile for both orientations. The presence of a successive pile had a strong effect and increased erosion. In other words, the total emitted mass would be underestimated if it was taken as twice the emissions calculated for an isolated stockpile. In addition, the piles oriented $60^{\circ}$ emitted larger amounts of mass than piles oriented $90^{\circ}$ in all configurations, especially for the $0.9 h$ gap. Therefore, the results may suggest that a larger single pile has less impact than two parallel piles. However, experiments with gaps larger than $1.8 h$ should be conducted.

The emission models of wind erosion are based on the local wall friction velocity which are well transposable at the real scales. Based on the work of Chew et al. [4] the Reynolds number of our experiments and numerical simulations (about 25000) satisfies the independence criterion. However, it is important to note that for studies involving atmospheric particle transport to describe the physics of particulate matter or sediment transport, scaling parameters considering particles characteristics should be considered. We propose for future works, studying the dispersion of emitted particles (multiphase flow), that the drag force and gravitational force on particles should satisfy similarity conditions. These days, few works are devoted to these investigations. 
Acknowledgements The authors acknowledge the financial support from Capes/Cofecub, Fapes and CNPq.

\section{References}

1. Andreotti, B, P Claudin, and O Pouliquen. 2010. Measurements of the aeolian sand transport saturation length. Geomorphology 123 (3-4): 343-348. doi:10.1016/j.geomorph.2010.08.002.

2. Badr, T, and J. L. Harion. 2005. Numerical modelling of flow over stockpiles: Implications on dust emissions. Atmospheric Environment 39 (30): 5576-5584. doi:10.1016/j.atmosenv.2005.05.053.

3. Badr, T, and Jean-Luc Harion. 2007. Effect of aggregate storage piles configuration on dust emissions. Atmospheric Environment 41 (2): 360-368. doi:10.1016/j.atmosenv.2006.07.038.

4. Chew, L. M., A. A. Aliabadi, and L. K. Norford. 2018. Flows across high aspect ratio street canyons: Reynolds number independence revisited. Environmental Fluid Mechanics.

5. Cong, X. C., S. L. Yang, S. Q. Cao, Z. L. Chen, M. X. Dai, and S. T. Peng. 2012. Effect of aggregate stockpile configuration and layout on dust emissions in an open yard. Applied Mathematical Modelling 36 (11): 5482-5491. doi:10.1016/j.apm.2012.01.014.

6. Diego, I, A Pelegry, S Torno, J Toraño, and M Menendez. 2009. Simultaneous CFD evaluation of wind flow and dust emission in open storage piles. Applied Mathematical Modelling 33 (7): 3197-3207. doi:10.1016/j.apm.2008.10.037.

7. Ferreira, A D, and M R Fino. 2012. A wind tunnel study of wind erosion and profile reshaping of transverse sand piles in tandem. Geomorphology 139140 (0): 230-241. doi:10.1016/j.geomorph.2011.10.024.

8. Ferreira, Almerindo D., and Rosebud J. Lambert. 2011. Numerical and wind tunnel modeling on the windbreak effectiveness to control the aeolian erosion of conical stockpiles. Environmental Fluid Mechanics 11 (1): 61-76. doi:10.1007/s10652-010-9176-x.

9. Fluent. 2001. ANSYS Gambit User's guide.

10. Fluent. 2013. ANSYS Fluent User's Guide.

11. Furieri, B., S. Russeil, J. L. Harion, J. Santos, and M. Milliez. 2012a. Comparative analysis of dust emissions: Isolated stockpile VS two nearby stockpiles. WIT Transactions on Ecology and the Environment 157. doi:10.2495/AIR120251. 9781845645823.

12. Furieri, B., S. Russeil, J. L. Harion, C. Turpin, and J. M. Santos. 2012b. Experimental surface flow visualization and numerical investigation of flow structure around an oblong stockpile. Environmental Fluid Mechanics 12 (6). doi:10.1007/s10652-012-9249-0.

13. Furieri, B., S. Russeil, J. M. Santos, and J. L. Harion. 2013. Effects of non-erodible particles on aeolian erosion: Wind-tunnel simulations of a sand oblong storage pile. Atmospheric Environment 79: 672-680. doi:10.1016/j.atmosenv.2013.07.026.

14. Gopalan, H, and R Jaiman. 2015. Numerical study of the flow interference between tandem cylinders employing non-linear hybrid URANS-LES meth- 
ods. Journal of Wind Engineering and Industrial Aerodynamics 142: 111-129. doi:10.1016/j.jweia.2015.03.017.

15. Grandemange, M, M Gohlke, and O Cadot. 2013. Turbulent wake past a threedimensional blunt body. Part 1. Global modes and bi-stability. Journal of Fluid Mechanics 722: 51-84. doi:10.1017/jfm.2013.83.

16. Huang, G, C Le Ribault, I Vinkovic, and S Simoens. 2017. Part I : a priori study of erosion and deposition with large eddy simulation of turbulent flow over multiple 2D sandy Gaussian hills. Environmental Fluid Mechanics. doi:10.1007/s10652-017-9552-x.

17. Kheirabadi, Hossein, Majid Mahmoodabadi, Vahidreza Jalali, and Hormozd Naghavi. 2018. Sediment flux, wind erosion and net erosion influenced by soil bed length, wind velocity and aggregate size distribution. Geoderma 323 (February): 22-30. doi:10.1016/j.geoderma.2018.02.042.

18. Kim, M K, D K Kim, S H Yoon, and D H Lee. 2008. Measurements of the flow fields around two square cylinders in a tandem arrangement. Journal of Mechanical Science and Technology 22 (2): 397-407. doi:10.1007/s12206-0071041-6.

19. Kok, J, and N Renno. 2006. Enhancement of the emission of mineral dust aerosols by electric forces. Geophysical research letters 33 (19): 1-5. doi:10.1029/2006GL026284.

20. Kurose, Ryoichi, and Satoru Komori. 2001. Turbulence structure over a particle roughness. International journal of multiphase flow 27 (4): 673-683.

21. Li, L, and L W Martz. 1995. Aerodynamic dislodgement of multiple-size sand grains over time. Sedimentology 42 (4): 683-694. doi:10.1111/j.13653091.1995.tb00400.x.

22. Lopes, A. M. G., L. A. Oliveira, Almerindo D. Ferreira, and J. P. Pinto. 2013. Numerical simulation of sand dune erosion. Environmental Fluid Mechanics 13 (2): 145-168. doi:10.1007/s10652-012-9263-2. ISBN 1567-7419.

23. Mollinger, A M, and $\mathrm{F} T \mathrm{~T}$ Nieuwstadt. 1996. Measurement of the lift force on a particle fixed to the wall in the sublayer of a fully developed turbulent boundary layer. Journal of Fluid Mechanics 316: 285-306. doi:10.1017/S0022112096000547.

24. Novak, L, B Bizjan, J Pražnikar, B Horvat, A Orbanić, and B Širok. 2015. Numerical Modeling of Dust Lifting from a Complex-Geometry Industrial Stockpile. Journal of Mechanical Engineering 61 (11): 621-631. doi:10.5545/svjme.2015.2824.

25. San, Bingbing, Yuanyuan Wang, and Ye Qiu. 2018. Numerical simulation and optimization study of the wind flow through a porous fence. Environmental Fluid Mechanics. doi:10.1007/s10652-018-9580-1. 10.1007/ s10652-018-9580-1.

26. Schlichting, Hermann. 1968. Boundary Layer Theory. McGraw-Hill Book Compagny.

27. Shao, Y, and H Lu. 2000. A simple expression for wind erosion threshold friction velocity. Journal of Geophysical Research: Atmospheres 105 (D17): 22437-22443.

28. Smith, Isaac B., Aymeric Spiga, and John W. Holt. 2015. Aeolian processes as drivers of landform evolution at the South Pole of Mars. Geomorphology 240: 54-69. doi:10.1016/j.geomorph.2014.08.026.

29. Swet, Nitzan, and Itzhak Katra. 2016. Reduction in soil aggregation 
in response to dust emission processes. Geomorphology 268: 177-183. doi:10.1016/j.geomorph.2016.06.002.

30. Torano, J. A., R. Rodriguez, I. Diego, J. M. Rivas, and A. Pelegry. 2007. Influence of the pile shape on wind erosion CFD emission simulation. Applied Mathematical Modelling 31 (11): 2487-2502. doi:10.1016/j.apm.2006.10.012.

31. Turpin, C. 2010. Amélioration des modèles de quantification des émissions particulaires diffuses liées à l'érosion éolienne de tas de stockage de matières granulaires sur sites industriels. PhD diss, Ecole des Mines de Douai, Université de Valenciennes et du Hainaut-Cambrésis.

32. Turpin, C, and J. L. Harion. 2009. Numerical modeling of flow structures over various flat-topped stockpiles height: Implications on dust emissions. Atmospheric Environment 43 (35): 5579-5587. doi:10.1016/j.atmosenv.2009.07.047.

33. Turpin, C, and J. L. Harion. 2010. Effect of the topography of an industrial site on dust emissions from open storage yards. Environmental Fluid Mechanics 10 (6): 677-690. doi:10.1007/s10652-010-9170-3.

34. Turpin, C, T Badr, and J. L. Harion. 2010. Numerical modelling of aeolian erosion over rough surfaces. Earth Surface Processes and Landforms 35 (12): 1418-1429. doi:10.1002/esp.1980.

35. USEPA. 2006. 13.2.5 Industrial Wind Erosion. Compilation of Air Pollutant Emission Factors, Volume I: Stationary Point and Area Sources, AP-42.

36. Van Doormaal, J P, and G D Raithby. 1984. Enhancements of the SIMPLE method for predicting incompressible fluid flows. Numerical heat transfer 7 (2): 147-163. doi:10.1080/01495728408961817.

37. Webb, Nicholas P., Magda S. Galloza, Ted M. Zobeck, and Jeffrey E. Herrick. 2016. Threshold wind velocity dynamics as a driver of aeolian sediment mass flux. Aeolian Research 20: 45-58. doi:10.1016/j.aeolia.2015.11.006. ISBN 18759637.

38. Yang, Fan, Xing Hua Yang, Wen Huo, Mamtimin Ali, Xin Qian Zheng, Cheng Long Zhou, and Qing He. 2017. A continuously weighing, high frequency sand trap: Wind tunnel and field evaluations. Geomorphology 293 (March): 84-92. doi:10.1016/j.geomorph.2017.04.008.

39. Yeh, Cheng Peng, Chien Hsiung Tsai, and Ruey Jen Yang. 2010. An investigation into the sheltering performance of porous windbreaks under various wind directions. Journal of Wind Engineering and Industrial Aerodynamics 98 (10-11): 520-532. doi:10.1016/j.jweia.2010.04.002.

40. Zdravkovich, M M. 1977. Review of flow interference between two circular cylinders in various arrangements. Journal of Fluids Engineering 99 (4): 618633. doi:10.1115/1.3448871. 


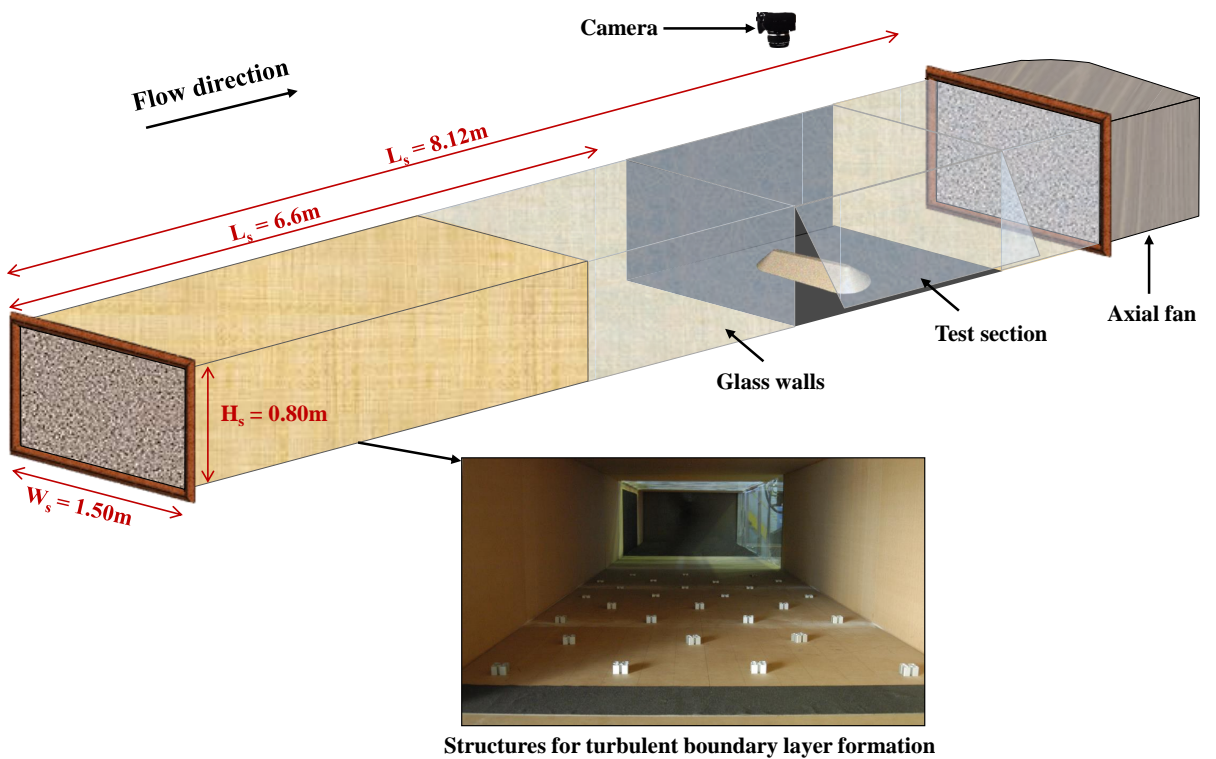

Fig. 1: Wind tunnel scheme 


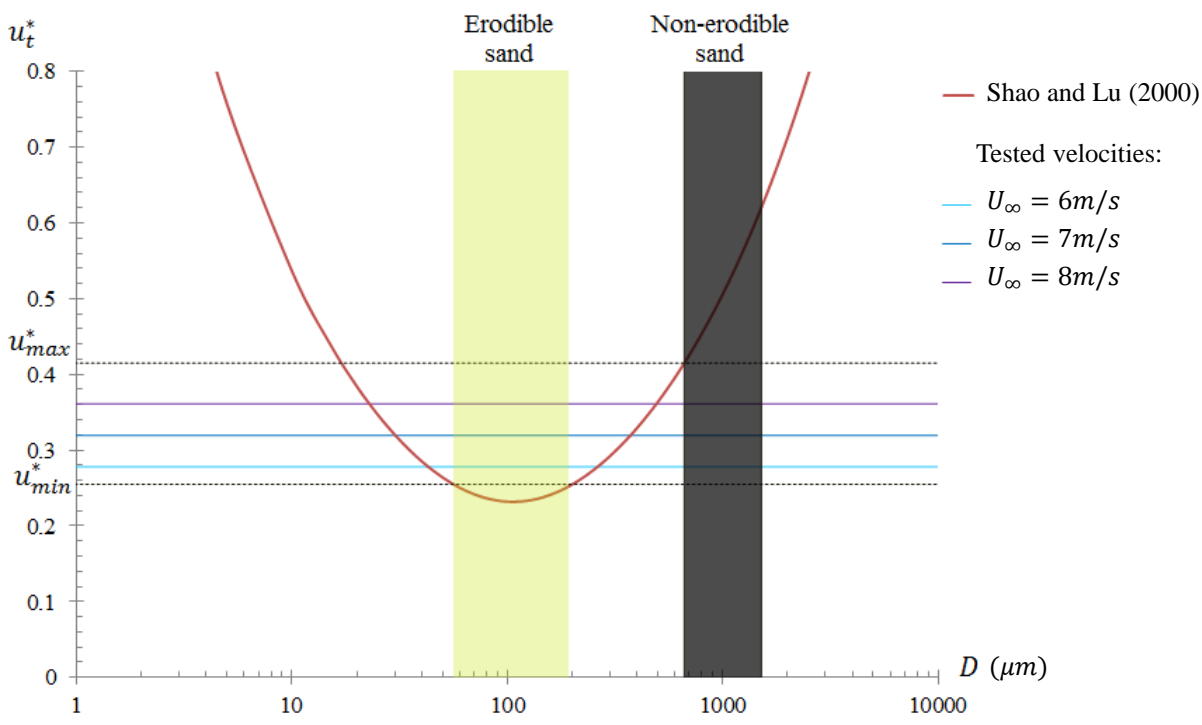

Fig. 2: Take-off criterion for a horizontal surface 


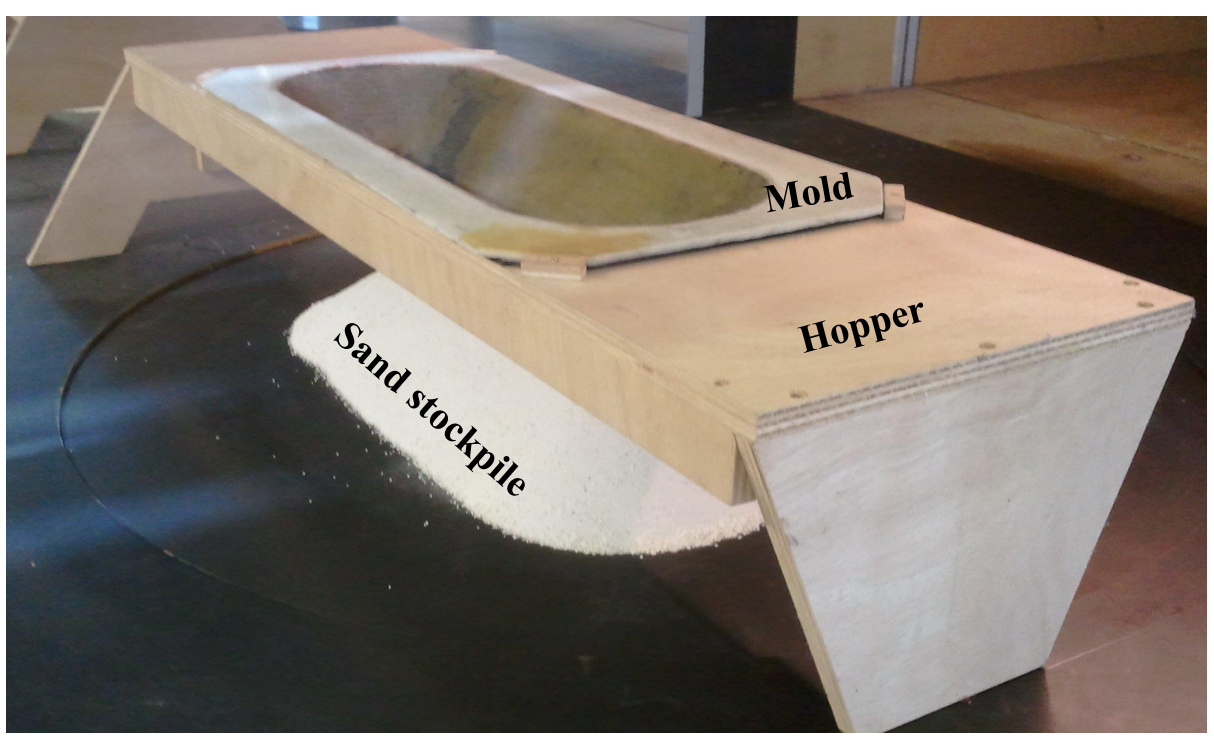

(a)

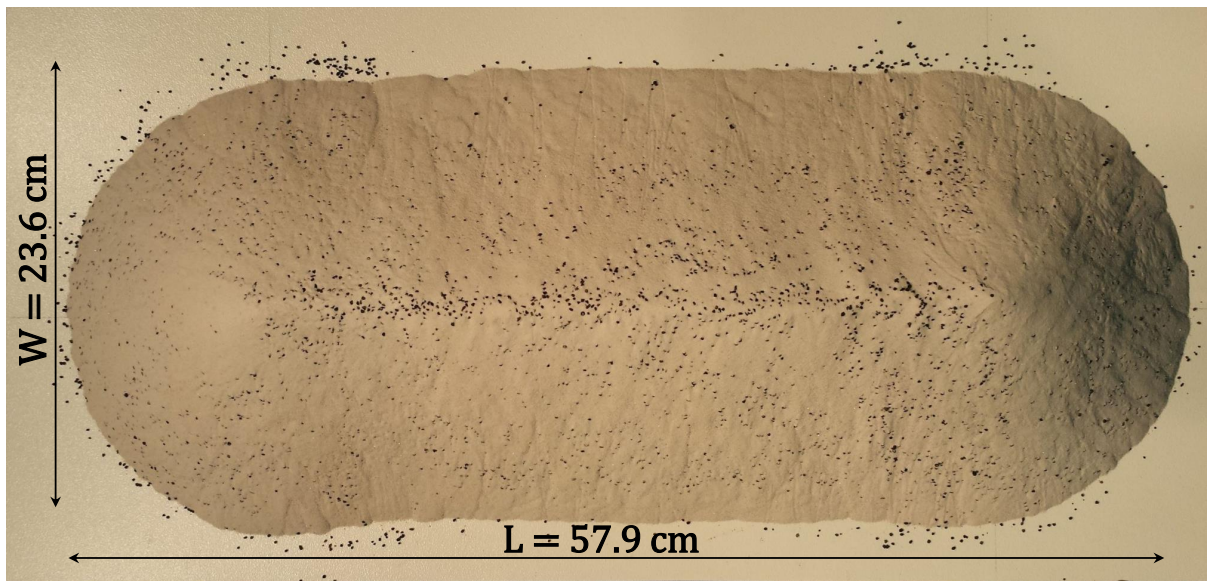

(b)

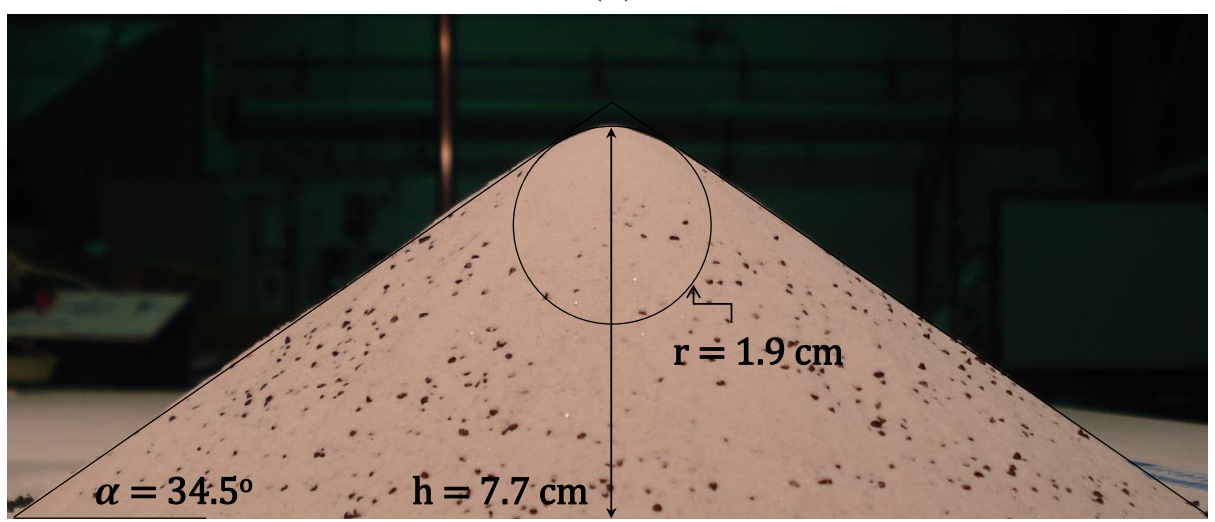

(c)

Fig. 3: (a) Device used for the construction of the sand stockpile model and the mean dimensions of the sand stockpile in (b) Top and (c) Side views 


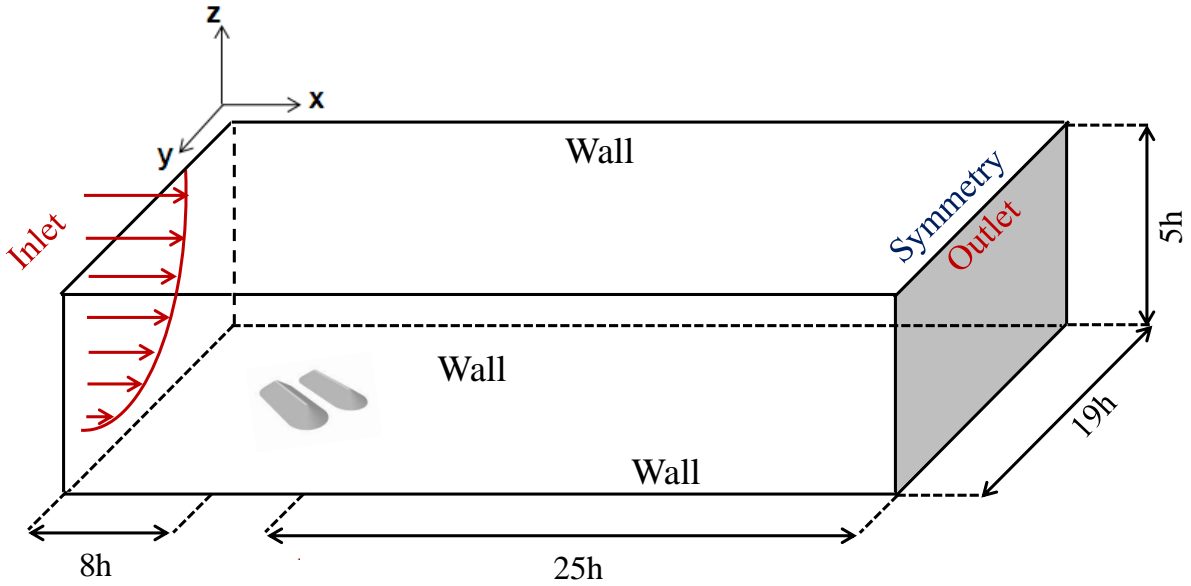

Fig. 4: Computational domain 


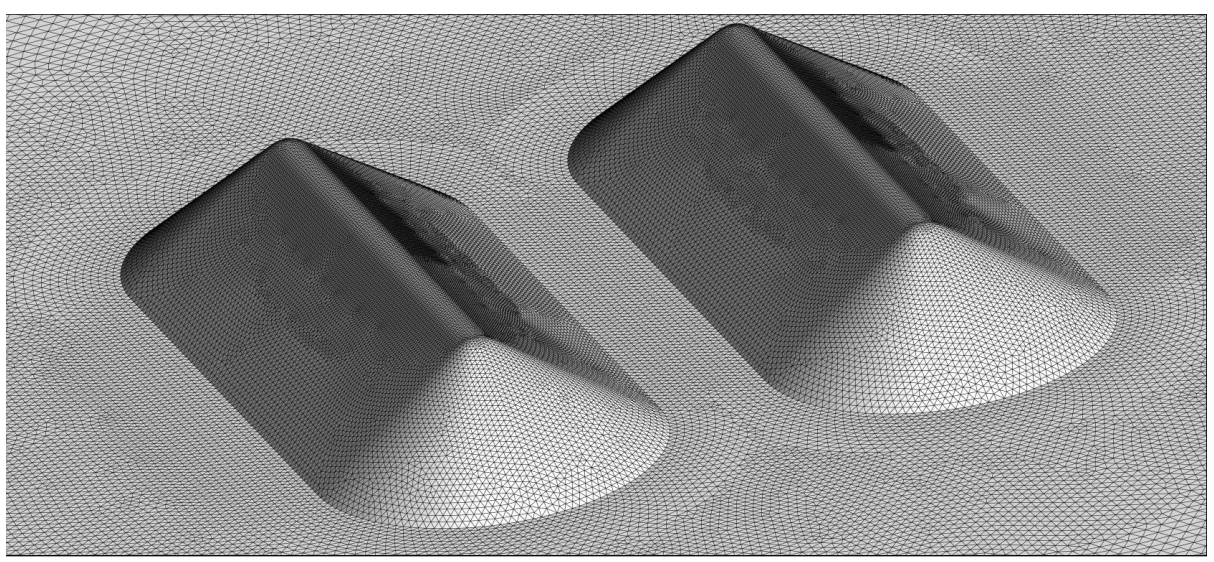

(a)

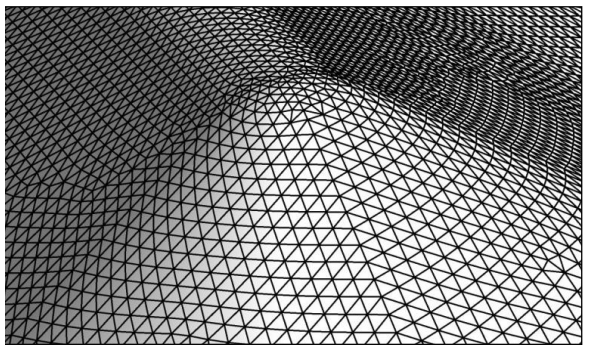

(b)

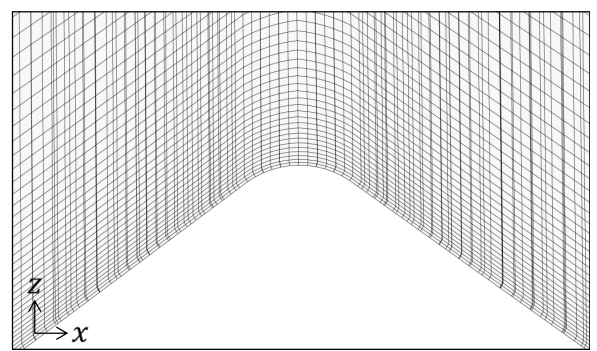

(c)

Fig. 5: (a) Perspective view of the mesh over the two piles, (b) Zoom of the mesh near the crest, and (c) Transversal cut of the domain over the pile 


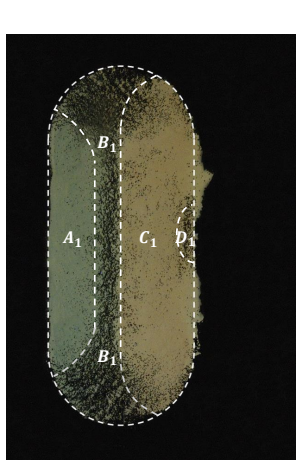

(a)
Wind flow direction
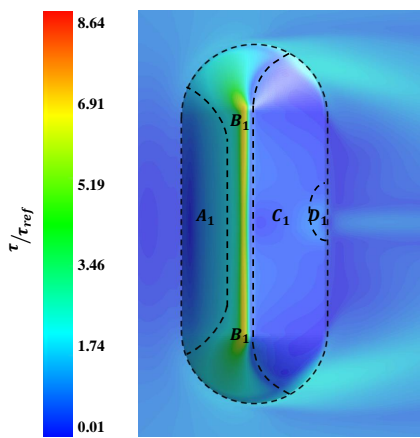

(b)

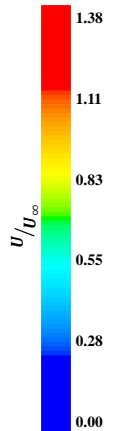

.55

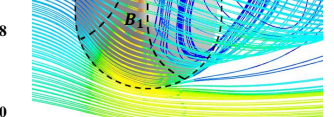

(c)

Fig. 6: Experimental and numerical results for an isolated stockpile (pile $p_{1}$ ) exposed to a perpendicular wind flow: (a) Top view of the eroded sand stockpile after the pavement phenomenon, (b) Mean wall shear stress on the pile surface and on the ground and (c) Mean flow pathlines over the pile. Four wind erosion regions are highlighted according to the degree of wind exposure: zones $A_{1}, B_{1}, C_{1}$ and $D_{1}$. 


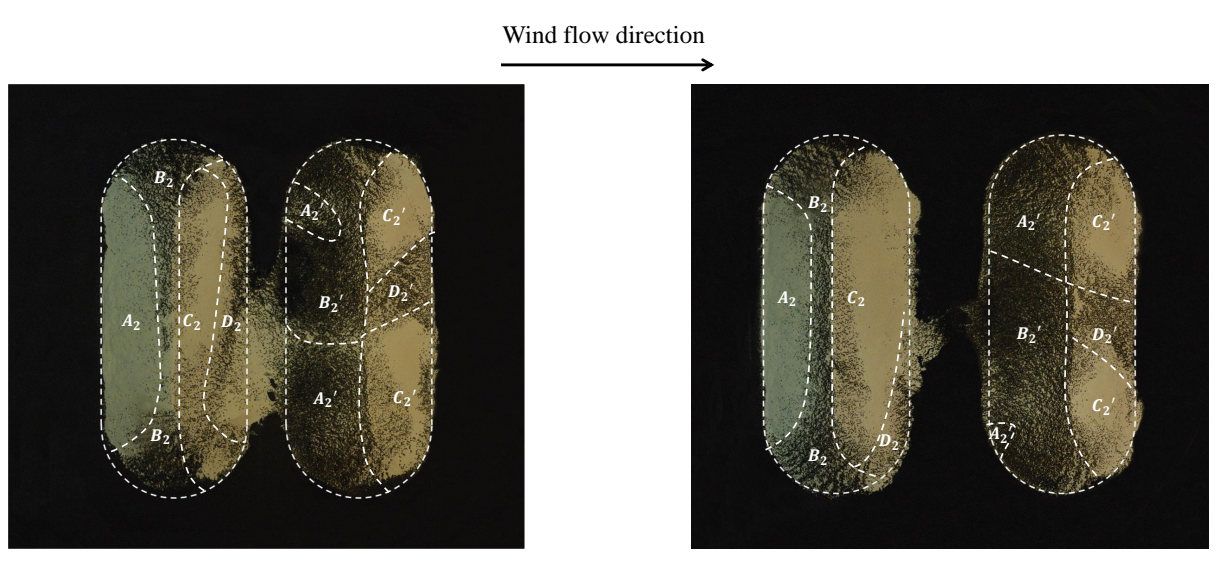

(a)
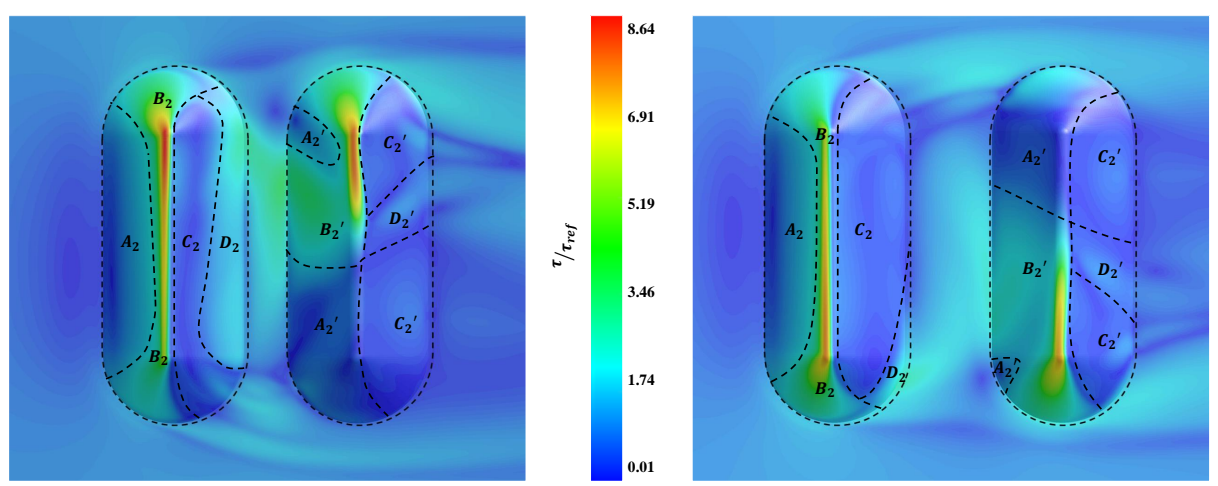

(b)
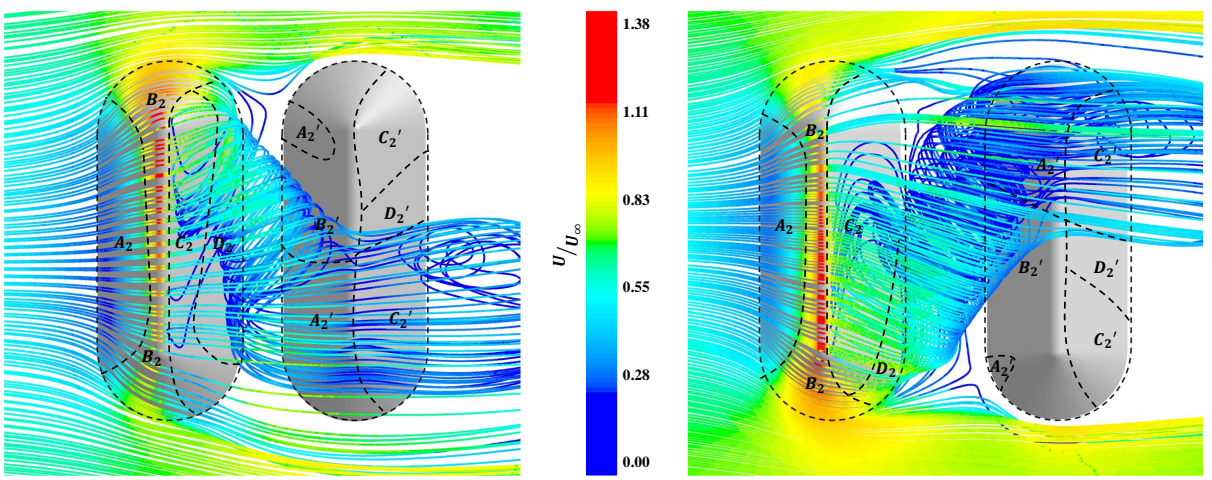

(c)

Fig. 7: Experimental and numerical results for two parallel stockpiles oriented $90^{\circ}$ separated by $0.9 h$ and $1.8 h$ gaps: (a) Top view of the eroded sand stockpiles after the pavement phenomenon, (b) Mean wall shear stress on the pile surfaces and on the ground and (c) Mean flow pathlines over the piles. Four wind erosion regions are highlighted on each pile, according to the degree of wind exposure: zones $A_{2}, B_{2}, C_{2}$ and $D_{2}$ in the upstream pile (pile $p_{2}$ ) and zones $A_{2}^{\prime}, B_{2}^{\prime}$, $C_{2}^{\prime}$ and $D_{2}^{\prime}$ in the downstream pile (pile $p_{2}^{\prime}$ ). 


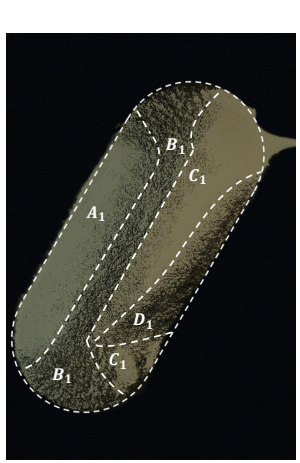

(a)
Wind flow direction

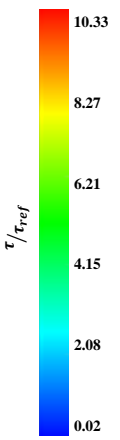
(1)

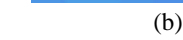

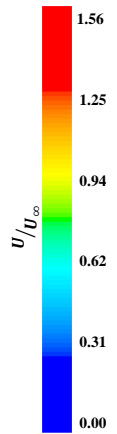

(b)

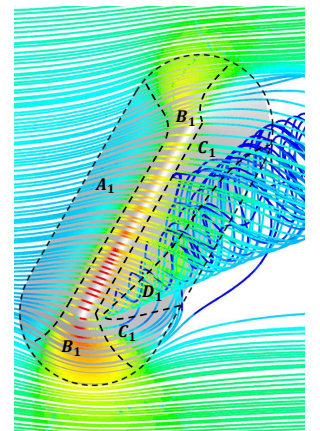

(c)

Fig. 8: Experimental and numerical results for an isolated stockpile (pile $p_{1}$ ) oriented $60^{\circ}$ to the main flow: (a) Top view of the eroded sand stockpile after the pavement phenomenon, (b) Mean wall shear stress on the pile surface and on the ground and (c) Mean flow pathlines over the pile. Four wind erosion regions are highlighted according to the degree of wind exposure: zones $A_{1}, B_{1}, C_{1}$ and $D_{1}$. 
$\stackrel{\text { Wind flow direction }}{\longrightarrow}$
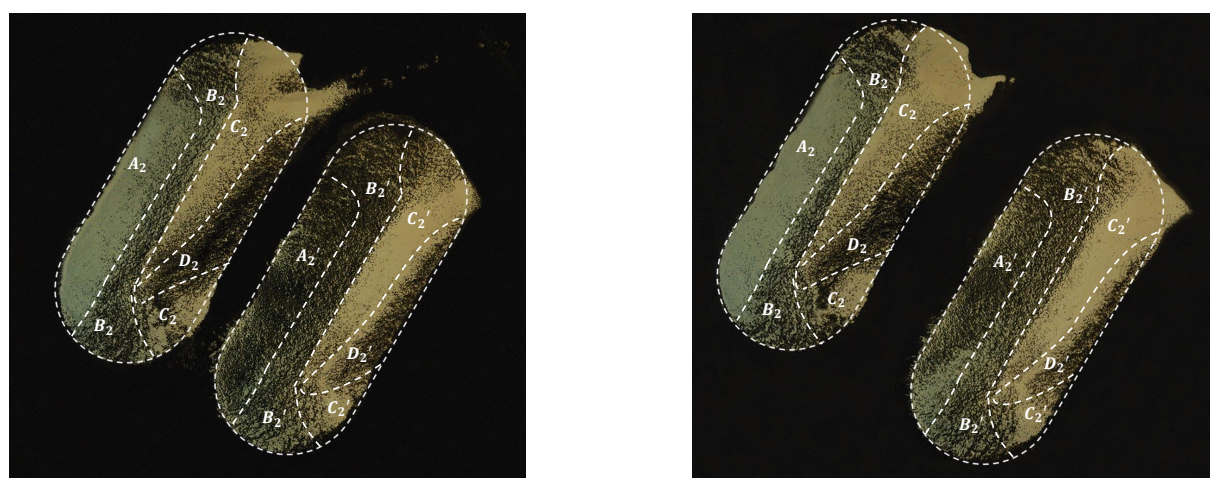

(a)
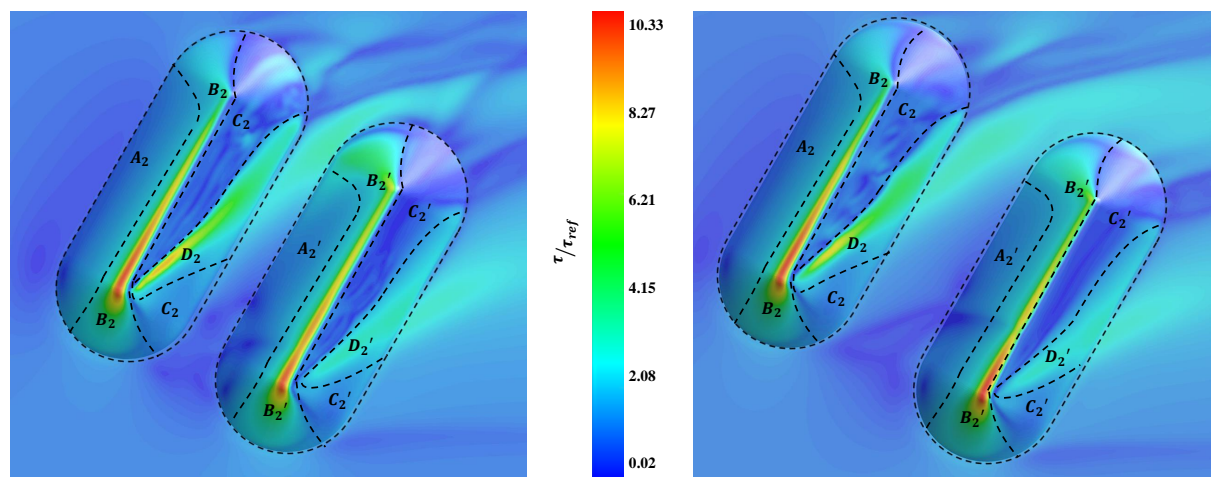

(b)
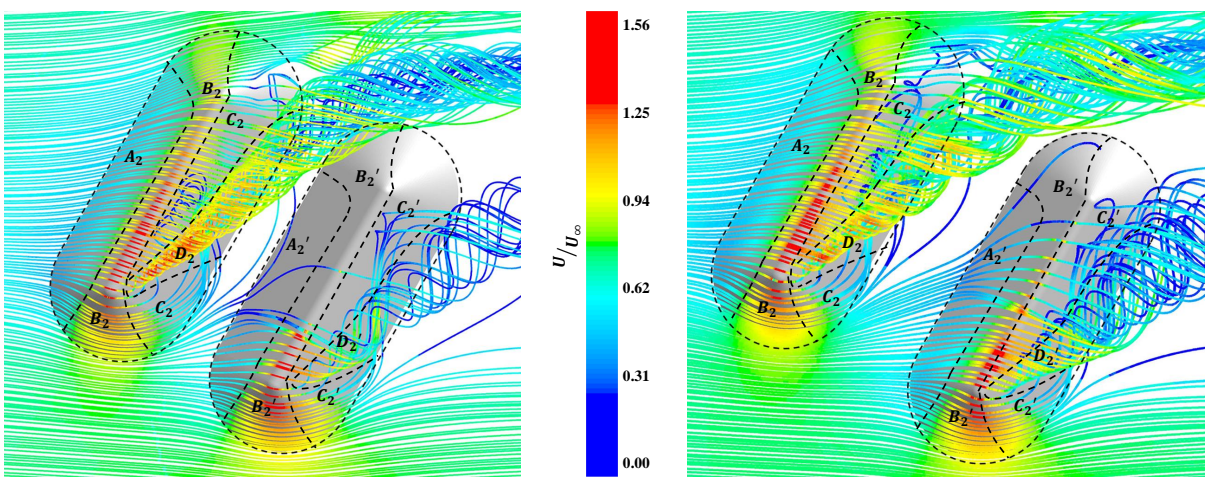

(c)

Fig. 9: Experimental and numerical results for two stockpiles oriented $60^{\circ}$ and separated by gaps $0.9 h$ and $1.8 h$ : (a) Top view of the eroded sand stockpiles after the pavement phenomenon, (b) Mean wall shear stress on the pile surface and on the ground and (c) Mean flow pathlines over the piles. Four wind erosion regions are highlighted on each pile, according to the degree of wind exposure: zones $A_{2}, B_{2}, C_{2}$ and $D_{2}$ in the upstream pile (pile $p_{2}$ ) and zones $A_{2}^{\prime}, B_{2}^{\prime}$, $C_{2}^{\prime}$ and $D_{2}^{\prime}$ in the downstream pile (pile $p_{2}^{\prime}$ ). 


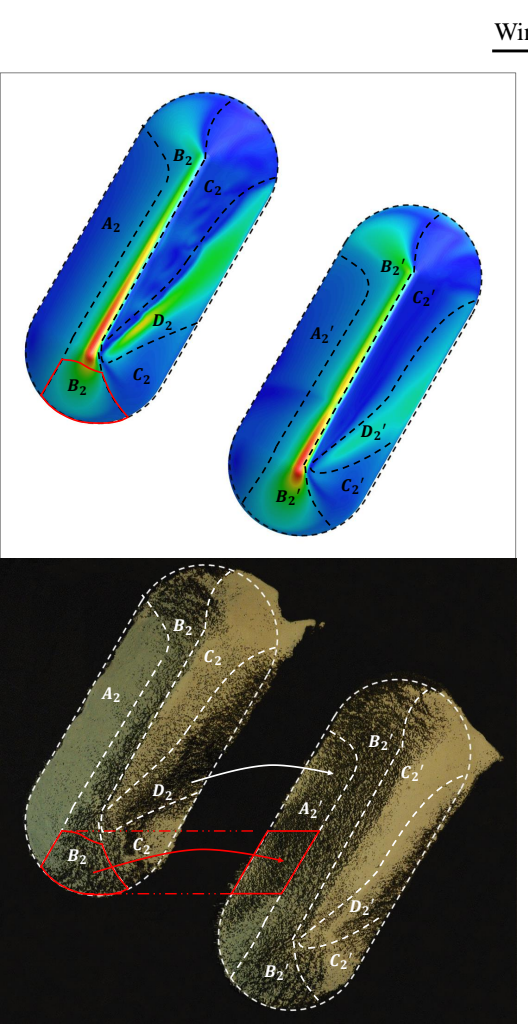

(a)
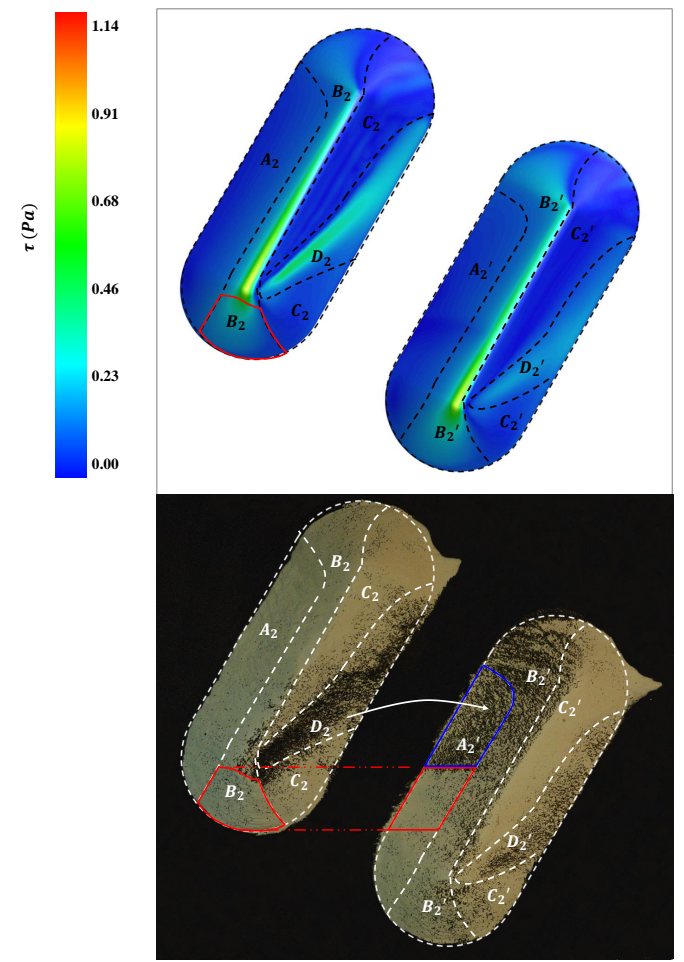

(b)

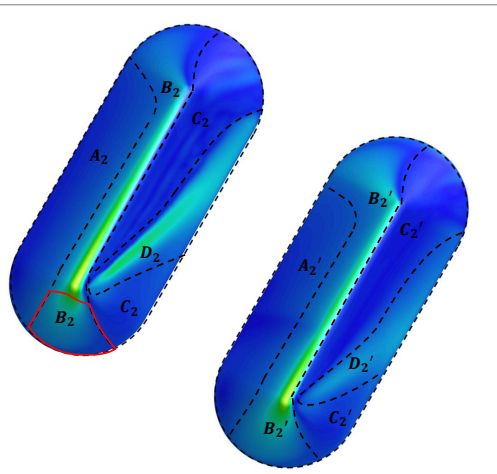

Fig. 10: Impact of the emitted particles from the upstream pile $p_{2}$ in two stockpiles oriented $60^{\circ}$ with $\alpha_{N E}=20 \%$ and separated by the $1.8 \mathrm{~h}$ gap for (a) $U_{\infty}=8 \mathrm{~m} / \mathrm{s}$ and (b) $U_{\infty}=6$ $\mathrm{m} / \mathrm{s}$ 

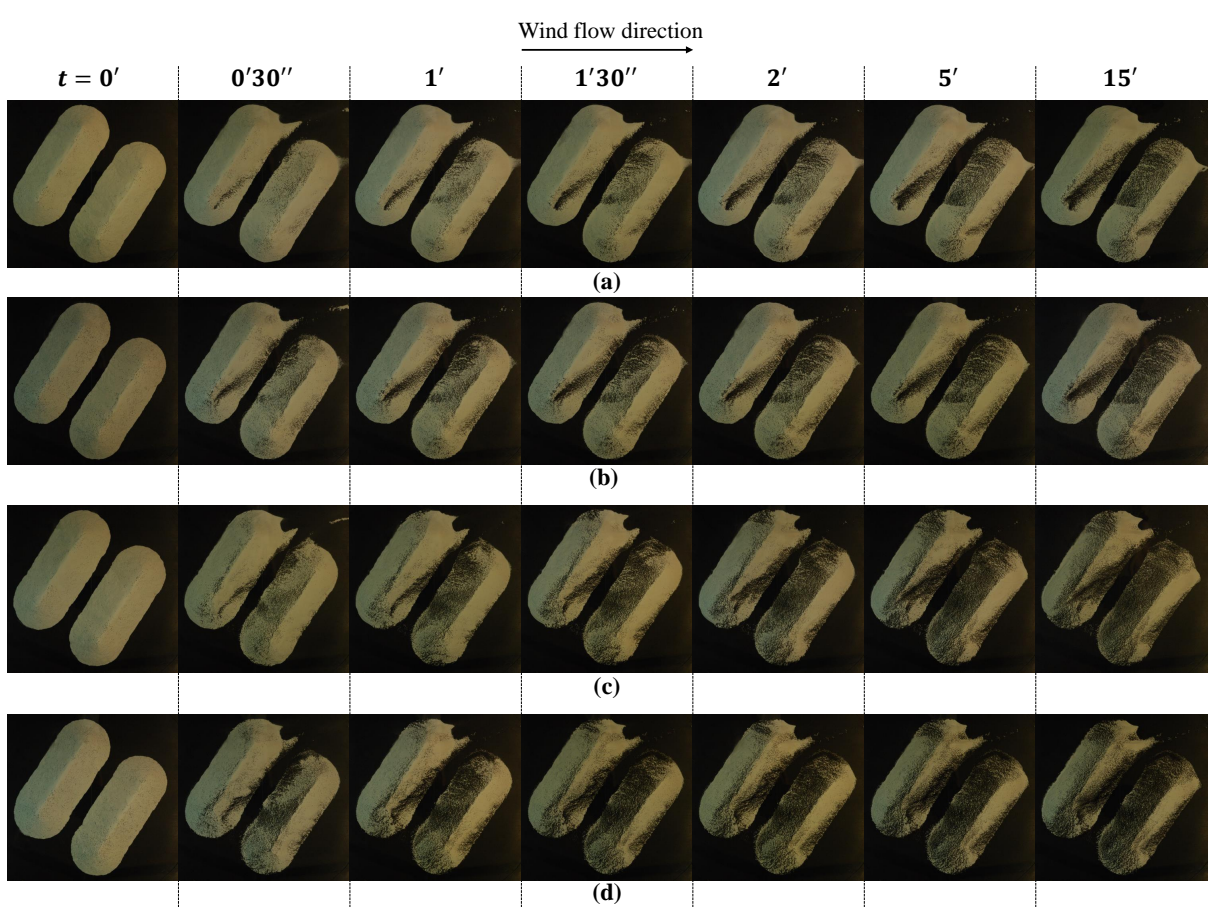

Fig. 11: Temporal evolution of the pavement phenomenon for two stockpiles oriented $60^{\circ}$ to the main flow separated by a $0.9 \mathrm{~h}$ gap: $U_{\infty}=6 \mathrm{~m} / \mathrm{s}$ with (a) $\alpha_{N E}=10 \%$ and (b) $\alpha_{N E}=20 \%$, $U_{\infty}=8 \mathrm{~m} / \mathrm{s}$ with (c) $\alpha_{N E}=10 \%$ and (d) $\alpha_{N E}=20 \%$ 


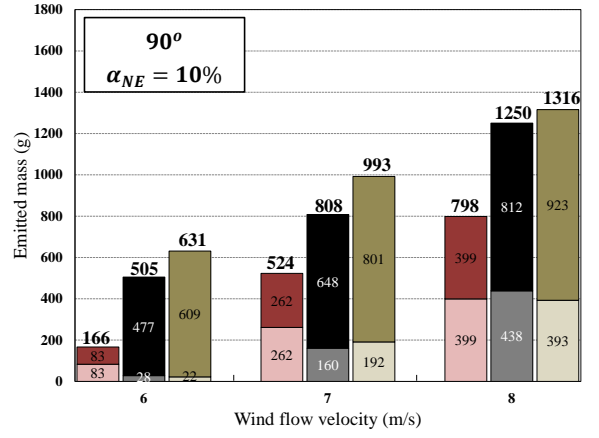

(a)

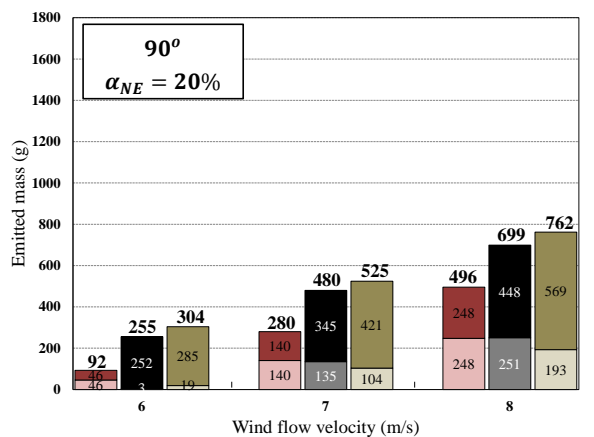

(c)

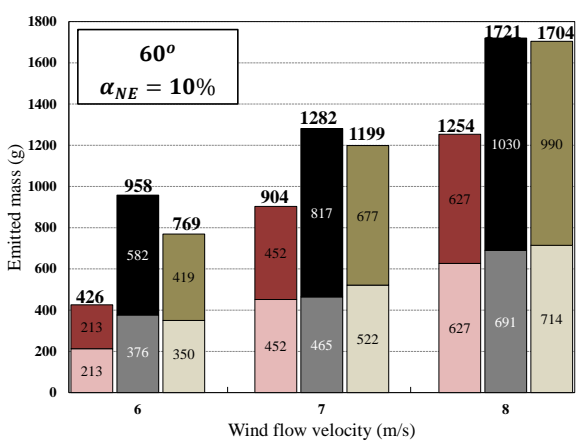

(b)

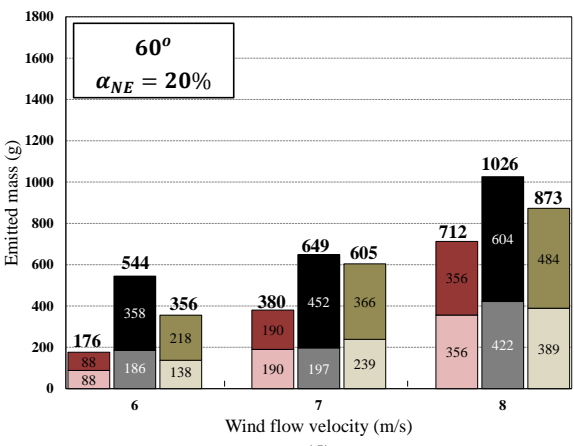

(d)

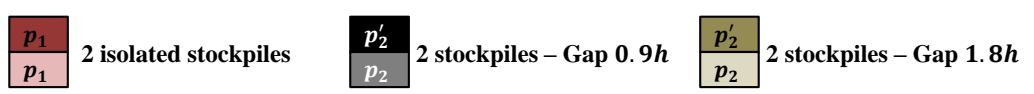

Fig. 12: Experimental quantification of the total amount of emitted mass from the successive stockpiles separated by the gaps of $0.9 h$ and $1.8 h$ compared to twice the amount from an isolated stockpile, for the configurations: $\alpha_{N E}=10 \%$ oriented (a) $90^{\circ}$ and (b) $60^{\circ}$, and $\alpha_{N E}=$ $20 \%$ oriented (c) $90^{\circ}$ and (d) $60^{\circ}$ 
Table 1: Tested configurations. The pile dimensions are: $7.7 \mathrm{~cm}$ of height, $23.6 \mathrm{~cm}$ of length and $57.9 \mathrm{~cm}$ of width

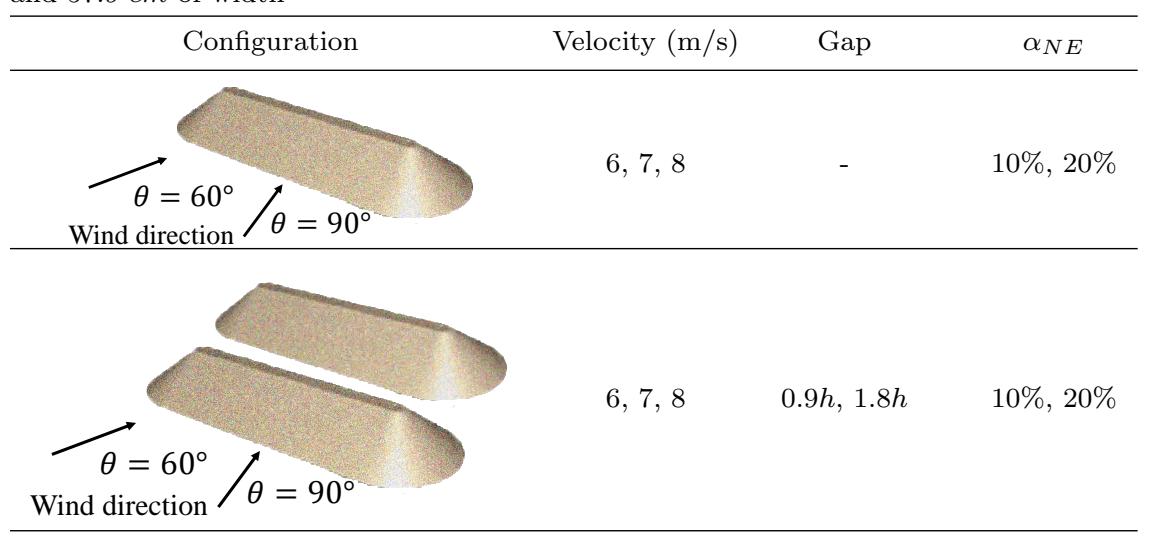


Table 2: Emitted mass measurements for an isolated stockpile and for two successive piles with gaps of $0.9 h$ and $1.8 h$ ( $h$ is the stockpile height)

\begin{tabular}{|c|c|c|c|c|c|c|c|c|}
\hline \multicolumn{2}{|c|}{ Configuration } & \multicolumn{2}{|c|}{$\begin{array}{l}\text { Emitted mass } \\
\text { pile } p_{1}(g)\end{array}$} & \multicolumn{5}{|c|}{$\begin{array}{c}\text { Emitted mass } \\
\text { successive piles }(g)\end{array}$} \\
\hline \multirow{2}{*}{$\begin{array}{c}\alpha_{N E} \\
(\%)\end{array}$} & \multirow{2}{*}{$\begin{array}{c}U_{\infty} \\
(m / s)\end{array}$} & \multirow{2}{*}{$90^{\circ}$} & \multirow{2}{*}{$60^{\circ}$} & \multirow{2}{*}{ Gap } & \multicolumn{2}{|c|}{$90^{\circ}$} & \multicolumn{2}{|c|}{$60^{\circ}$} \\
\hline & & & & & pile $p_{2}$ & pile $p_{2}^{\prime}$ & pile $p_{2}$ & pile $p_{2}^{\prime}$ \\
\hline \multirow{6}{*}{10} & \multirow{2}{*}{6} & \multirow{2}{*}{83.2} & \multirow{2}{*}{212.9} & $0.9 h$ & 27.8 & 477.1 & 376.3 & 581.6 \\
\hline & & & & $1.8 h$ & 22.2 & 609.0 & 350.3 & 418.7 \\
\hline & \multirow{2}{*}{7} & \multirow{2}{*}{261.6} & \multirow{2}{*}{451.8} & $0.9 h$ & 160.4 & 647.9 & 464.6 & 816.7 \\
\hline & & & & $1.8 h$ & 191.5 & 801.0 & 521.7 & 677.1 \\
\hline & \multirow{2}{*}{8} & \multirow{2}{*}{399.2} & \multirow{2}{*}{626.6} & $0.9 h$ & 438.4 & 811.8 & 690.5 & 1029.8 \\
\hline & & & & $1.8 h$ & 393.1 & 922.9 & 714.3 & 989.9 \\
\hline \multirow{6}{*}{20} & \multirow{2}{*}{6} & \multirow{2}{*}{46.3} & \multirow{2}{*}{88.2} & $0.9 h$ & 3.2 & 252.0 & 186.4 & 358.2 \\
\hline & & & & $1.8 h$ & 18.7 & 285.4 & 137.5 & 218.1 \\
\hline & \multirow{2}{*}{7} & \multirow{2}{*}{140.3} & \multirow{2}{*}{190.1} & $0.9 h$ & 135.4 & 345.2 & 197.1 & 451.7 \\
\hline & & & & $1.8 h$ & 103.6 & 420.7 & 238.7 & 365.7 \\
\hline & \multirow{2}{*}{8} & \multirow{2}{*}{247.8} & \multirow{2}{*}{356.4} & $0.9 h$ & 250.7 & 448.3 & 421.9 & 604.1 \\
\hline & & & & $1.8 h$ & 192.9 & 569.1 & 389.0 & 483.7 \\
\hline
\end{tabular}

